Florida International University

FIU Digital Commons

FIU Electronic Theses and Dissertations

University Graduate School

10-22-2009

\title{
Stereotype Threat and the Standardized Testing Experiences of African American Children at an Urban Elementary School
}

Martin J. Wasserberg

Florida International University, mwasserb@gmail.com

DOI: $10.25148 /$ etd.FI09120815

Follow this and additional works at: https://digitalcommons.fiu.edu/etd

Part of the Curriculum and Instruction Commons, Educational Assessment, Evaluation, and $\underline{\text { Research Commons, Elementary Education and Teaching Commons, Race and Ethnicity }}$ Commons, Social and Philosophical Foundations of Education Commons, Social Psychology Commons, and the Urban Education Commons

\section{Recommended Citation}

Wasserberg, Martin J., "Stereotype Threat and the Standardized Testing Experiences of African American Children at an Urban Elementary School" (2009). FIU Electronic Theses and Dissertations. 116.

https://digitalcommons.fiu.edu/etd/116 


\section{FLORIDA INTERNATIONAL UNIVERSITY}

Miami, Florida

\section{STEREOTYPE THREAT AND THE STANDARDIZED TESTING EXPERIENCES OF AFRICAN AMERICAN CHILDREN AT AN URBAN ELEMENTARY SCHOOL}

A dissertation submitted in partial fulfillment of the requirements for the degree of DOCTOR OF PHILOSOPHY

in CURRICULUM AND INSTRUCTION

by

Martin J. Wasserberg 
To: Interim Dean Marie McDemmond

College of Education

This dissertation, written by Martin J. Wasserberg, and entitled Stereotype Threat and the Standardized Testing Experiences of African American Children at an Urban Elementary School, having been approved in respect to style and intellectual content, is referred to you for judgment.

We have read this dissertation and recommend that it be approved.

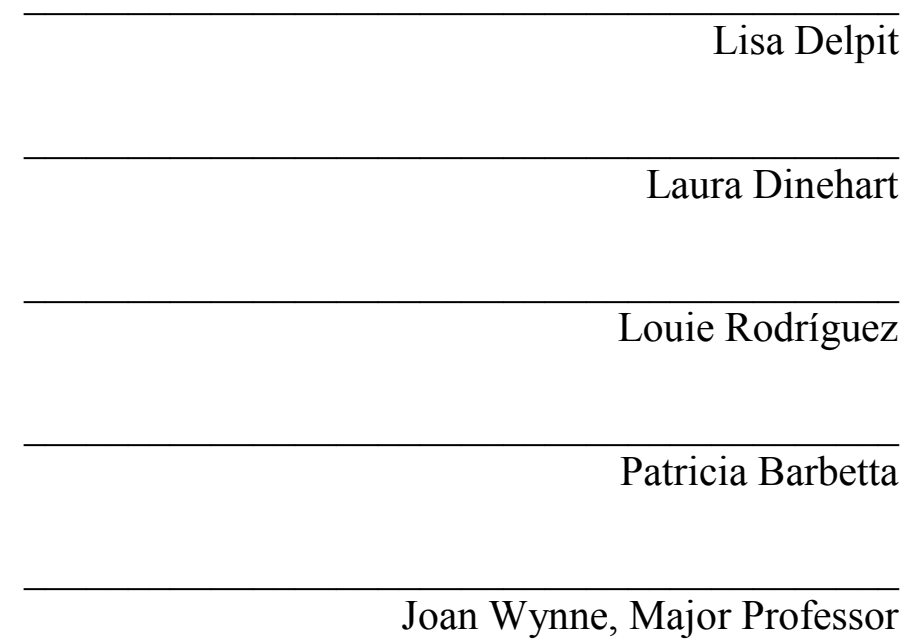

Date of Defense: October 22, 2009

The dissertation of Martin J. Wasserberg is approved.

Interim Dean Marie McDemmond

College of Education

Dean George Walker

University Graduate School

Florida International University, 2009 
(C) Copyright 2009 by Martin J. Wasserberg

All rights reserved. 


\section{DEDICATION}

Dedicated to my mother, my father, and the rest of my family who have always supported my dreams. Thank you for your love and support. I love you very much.

To my beautiful wife, Ethel, and to my unborn child, you are my inspiration. I love you more than you can imagine.

To my past students, I take this journey with you at heart. Your smiles, sometimes despite great personal challenges, are the reason I move forward. 


\section{ACKNOWLEDGMENTS}

I would like to thank all those who helped me reach my goal on this journey. I would like to first thank my wonderful faculty committee. Dr. Wynne, your constant support and encouragement were a necessary part of my success. Dr. Rodríguez, your mentorship and dedication provided me with a model for my future. Dr. Dinehart, I thank you for patience and help, I couldn't have struggled through the statistical analyses without you. Dr. Delpit, your expertise and encouraging words always gave me confidence I was on the right track.

To all my other professors, administrators, and colleagues, I would not have made it this far without your support.

This research was supported by the Doctoral Evidence Acquisition Fellowship and the Dissertation Year Fellowship generously awarded by Florida International University. 
ABSTRACT OF THE DISSERTATION

\title{
STEREOTYPE THREAT AND THE STANDARDIZED TESTING EXPERIENCES OF \\ AFRICAN AMERICAN STUDENTS AT AN URBAN ELEMENTARY SCHOOL
}

\author{
by
}

\author{
Martin J. Wasserberg \\ Florida International University, 2009 \\ Miami, Florida \\ Professor Joan Wynne, Major Professor
}

Stereotype threat (Steele \& Aronson, 1995) refers to the risk of confirming a negative stereotype about one's group in a particular performance domain. The theory assumes that performance in the stereotyped domain is most negatively affected when individuals are more highly identified with the domain in question. As federal law has increased the importance of standardized testing at the elementary level, it can be reasonably hypothesized that the standardized test performance of African American children will be depressed when they are aware of negative societal stereotypes about the academic competence of African Americans.

This sequential mixed-methods study investigated whether the standardized testing experiences of African American children in an urban elementary school are related to their level of stereotype awareness. The quantitative phase utilized data from 198 African American children at an urban elementary school. Both ex-post facto and experimental designs were employed. Experimental conditions were diagnostic and nondiagnostic testing experiences. The qualitative phase utilized data from a series of six focus group interviews conducted with a purposefully selected group of 4 African 
American children. The interview data were supplemented with data from 30 hours of classroom observations.

Quantitative findings indicated that the stereotype threat condition evoked by diagnostic testing depresses the reading test performance of stereotype-aware African American children $(F[1,194]=2.21, p<.01)$. This was particularly true of students who are most highly domain-identified with reading $(F[1,91]=19.18, p<.01)$. Moreover, findings indicated that only stereotype-aware African American children who were highly domain-identified were more likely to experience anxiety in the diagnostic condition $(F[1,91]=5.97, p<.025)$.

Qualitative findings revealed 4 themes regarding how African American children perceive and experience the factors related to stereotype threat: (1) a narrow perception of education as strictly test preparation, (2) feelings of stress and anxiety related to the state test, (3) concern with what "others" think (racial salience), and (4) stereotypes. A new conceptual model for stereotype threat is presented, and future directions including implications for practice and policy are discussed. 


\section{TABLE OF CONTENTS}

CHAPTER

PAGE

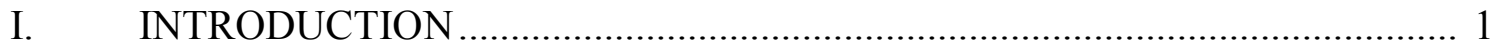

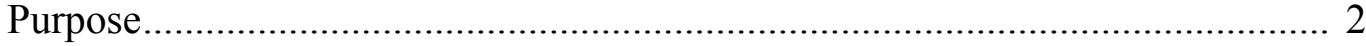

Derivation of Research Questions and Hypotheses .............................................. 2

Research Questions and Hypotheses ................................................................... 3

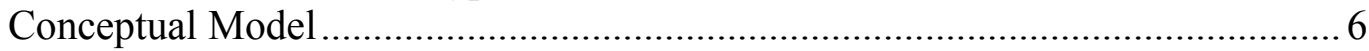

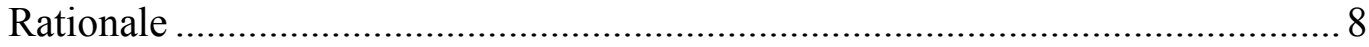

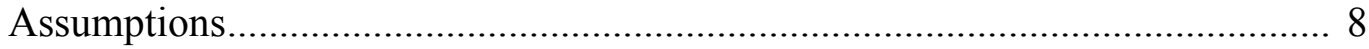

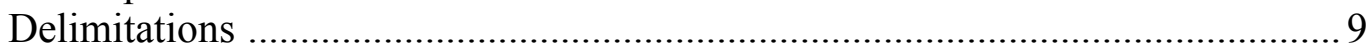

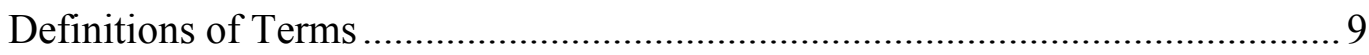

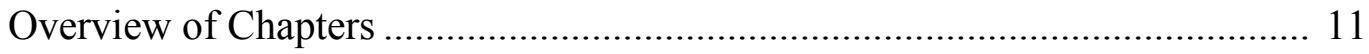

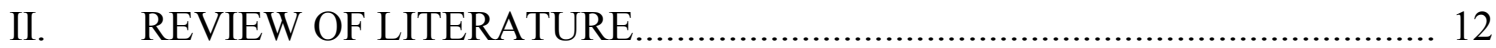

Stereotype Threat ...................................................................................... 13

Critical Race Theory in Education.................................................................. 26

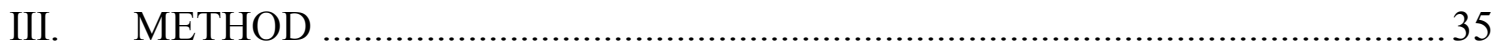

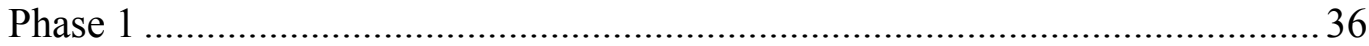

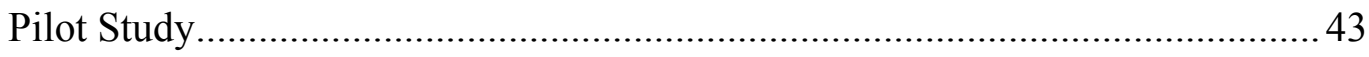

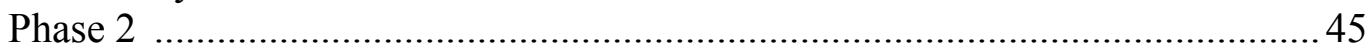

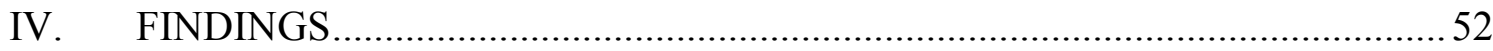

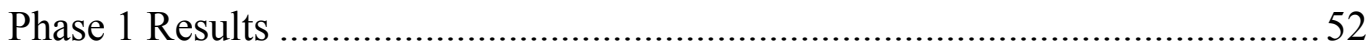

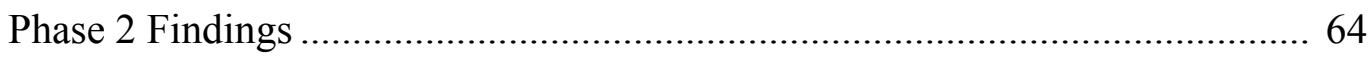

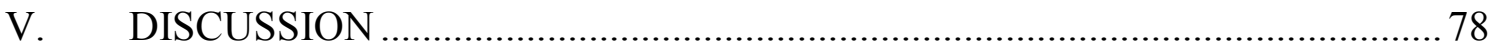

A New Conceptual Model ...............................................................................79

Implications for Educators ........................................................................... 82

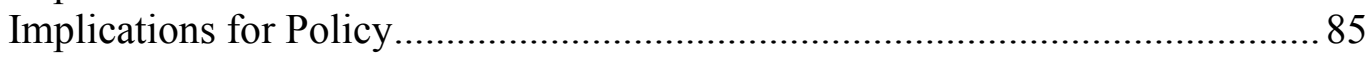

Limitations of the Study.............................................................................. 99

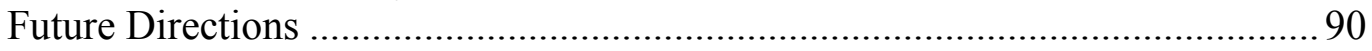

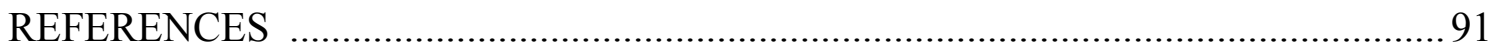

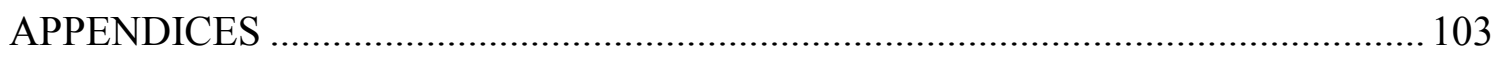

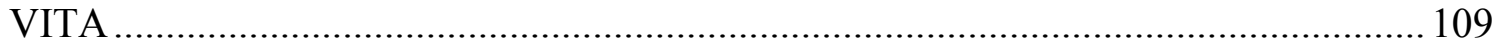




\section{LIST OF TABLES}

TABLE

PAGE

1. Research Suggesting that Stereotype Threatening Situations Depress Performance .. 14

2. Number of Participants in Each Condition Broken Down by Grade Level.................53

3. Participant Scores on the English Subsection of the Domain Identification Measure by

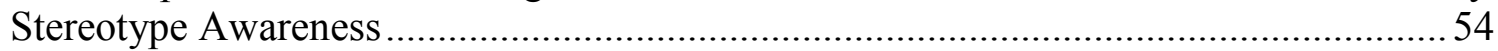

4. Descriptive Statistics on Dependent Variable Measures for Stereotype Aware

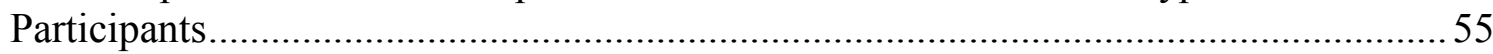

5. Descriptive Statistics on Dependent Variable Measures for Not Stereotype Aware

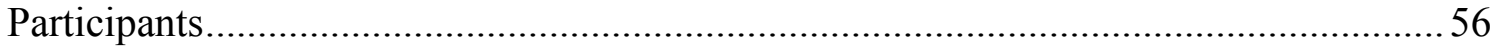

6. Descriptive Statistics on Dependent Variable Measures for All Participants..............57 


\section{LIST OF FIGURES}

FIGURE

PAGE

1. Mechanisms that may moderate and mediate stereotype threat effects ..................... 7

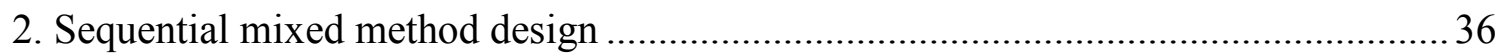

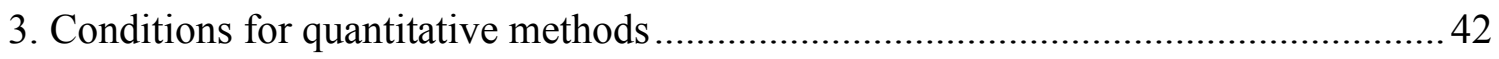

4. Effect of threat condition on the reading test performance of African American

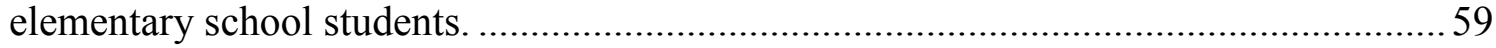

5. Influence of domain-identification on the stereotype threat reading test performance effects for stereotype-aware African American elementary school students..................61

6. Influence of domain-identification on the stereotype threat pre-test anxiety for stereotype-aware African American elementary school students................................6 65

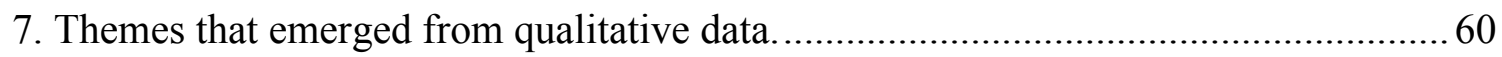

8. A new conceptual model for stereotype threat. ................................................... 80 


\section{CHAPTER I}

\section{INTRODUCTION}

The standardized test performance of African American students has long been a serious concern and source of debate (Herrnstein \& Murray, 1994; Jencks \& Phillips, 1998). The dominant discourse (e. g. Thernstrom \& Thernstrom, 2003) largely focuses on a cultural deficit model to explain the racial test score gap. ${ }^{1}$ Such an explanation downplays the effect of racial stereotyping and students' subsequent responses. The possibility of being judged in terms of a stereotype has been shown to significantly depress the performance of African American students at all levels (McKown \& Weinstein, 2003; Steele \& Aronson, 1995). Importantly, such research has demonstrated that racial performance gaps may be in part a product of processes amenable to intervention.

The No Child Left Behind Act (2002) has substantially increased the importance of standardized testing at the elementary grades (U.S. Department of Education, 2007). This has lead to an unbalanced focus on test practice curricular protocols, as opposed to more diverse pedagogies, especially in elementary schools serving primarily African American students (Cawelti, 2006; Kozol, 2005). Steele (1997) has suggested that as African American students become more invested in the outcome of standardized tests, negative stereotypes become increasingly salient, and their performance suffers.

\footnotetext{
${ }^{1}$ The term "test score gap" is used in place of "achievement gap" in this dissertation to indicate that it is solely in reference to gaps in standardized test scores, which are not the only measure of "achievement." The author recognizes the "achievement gap" characterization as problematic, in that it (a) infers that the burden for underperformance is solely students', and (b) it uses White students' normative performance as a universal standard (see Hilliard, 2003) The terms "opportunity gap" or "resource gap" could better characterize the totality of the phenomenon in many cases by placing the burden for underperformance where the author believes it more rightly belongs.
} 


\section{Purpose}

The purpose of this study was to analyze the influence of societal stereotypes on the standardized testing experiences of African American students in an urban elementary school that has adopted test-practice curricular protocols.

\section{Derivation of Research Questions and Hypotheses}

Stereotype threat (Steele \& Aronson, 1995) refers to the risk of confirming a negative stereotype about one's group in a particular performance domain (e.g., standardized testing). Stereotype threat theory assumes that underperformance is triggered by the possibility of being judged in terms of said stereotype. Given the possibility of positive intervention (e.g., Aronson, Fried, \& Good, 2002; Cohen, Garcia, Apfel, \& Master, 2006; Good, Aronson, \& Inzlicht, 2003), a necessary next step is to examine how and when children begin to experience negative effects. This would seem to be of particular importance when addressing potential remedies for the racial gap in standardized test scores, especially since grade promotion is highly contingent upon test performance at the elementary level (U.S. Department of Education, 2007).

African American children are targeted by a negative stereotype of intellectual inferiority in all academic areas (Steele, 1997). This negative racial stereotype is made salient in a standardized testing situation, thereby impeding performance and causing African American elementary students to perform more poorly than they would in a neutral context (McKown \& Weinstein, 2003, Study 2). However, past research on stereotype threat effects on African American children failed to take into account domain-identification (Steele, 1997). That is, when a student tied his or her identity to his or her performance on a standardized test, a negative stereotype was more threatening 
and influential on performance. In such cases, students who were more domain-identified would not only have traditional testing concerns, but also the added pressure of not confirming a prevailing stereotype about their group. Individuals most affected by stereotype threat were highly identified with the domain in question (Spencer, Steele, \& Quinn, 1999; Steele). The extra pressure associated with awareness of a negative stereotype about one's group thus had greater effect on a subset of the stereotyped group that more closely tied their identity to the standardized test results.

Research Questions and Hypotheses

The overarching research question that guided the study was: Are the standardized testing experiences of African American children in an urban elementary school related to their level of stereotype awareness? This research question was broken down into several specific subquestions and hypotheses:

1. Is the reading test performance of African American elementary school students related to their awareness of racial stereotypes? Specifically, does a diagnostic situation have an influence on the reading test performance of African American elementary school students aware of negative racial stereotypes?

Awareness of a threatening societal stereotype is a prerequisite for stereotype threat effects (Steele, 1997). Therefore, it was hypothesized that only when African American elementary school students are aware of the societal stereotype of African American intellectual inferiority will a diagnostic testing situation be threatening to them in this respect. Specifically, it was hypothesized that stereotype-aware students will significantly underperform on a reading comprehension activity framed as a test 
diagnostic of intelligence, as compared to when the same activity is framed as nondiagnostic of intelligence.

2. (a) Is level of domain-identification with reading related to the test performance of African American elementary school students?

Overall, it was hypothesized that African American elementary school students who are more domain-identified with reading will perform better on a reading test than African American elementary school students less domain-identified with reading. (b) Specifically, is level of domain-identification with reading related to the influence of a diagnostic testing situation on the reading test performance of African American elementary school students aware of racial stereotypes? It had already been hypothesized that stereotype-aware African American elementary school students will underperform on a reading comprehension activity when it is framed as diagnostic of intelligence. This additional hypothesis specified that when subjected to diagnostic testing conditions, students who are more domain-identified with reading will experience more of a comparative underperformance than their counterparts who are less domain-identified with reading. That is, it is hypothesized that the pressure of diagnostic testing has a more significant negative effect on the subset of stereotypeaware students who more closely tie their identity to the reading test results.

3. Are the anxiety, self-efficacy, and achievement goal orientation of African American elementary school students related to their awareness of racial stereotypes? Specifically, does a diagnostic situation have an influence on the anxiety, self-efficacy, and achievement goal orientation of African American elementary school students aware of racial stereotypes? 
It was hypothesized that participants in diagnostic conditions will report higher levels of anxiety, and lower levels of self-efficacy than participants in nondiagnostic conditions. In respect to stereotype threat, awareness of a threatening societal stereotype is a prerequisite for stereotype threat effects (Steele, 1997). Therefore, it was hypothesized that only when African American elementary school students are aware of the societal stereotype of African American intellectual inferiority will a diagnostic testing situation be threatening to them in this respect. Specifically, it was hypothesized that stereotype-aware participants in diagnostic conditions will report significantly higher levels of orientation towards a performance-avoidance achievement goal, higher levels of anxiety, and lower levels of self-efficacy when a reading comprehension activity is framed as a test diagnostic of intelligence, than participants in diagnostic conditions who are not stereotype-aware.

4. Is level of domain-identification with reading specifically related to the influence of a diagnostic testing situation on the anxiety, self-efficacy, and achievement goal orientation of African American elementary school students aware of racial stereotypes?

This additional hypothesis specified that when subjected to diagnostic testing conditions, stereotype-aware students who are more domain-identified with reading would report higher levels of anxiety, lower levels of self-efficacy, and be more likely to report a performance-avoidance achievement goal than participants who are less domainidentified.

Whereas subquestions 1 through 4 were investigated using quantitative methods, the final subquestion was investigated using qualitative methods. 
5. How do African American children perceive and experience the factors related to stereotype threat and navigate through the school year approaching the standardized test?

\section{Conceptual Model}

A conceptual model has been developed to clarify, and further explain the reasoning behind the hypotheses (see Figure 1). Research suggests that stereotype awareness (McKown \& Weinstein, 2003, Study 1) is a prerequisite of stereotype threat experiences, and that identity salience (one's consciousness of one's stereotyped identity; Inzlicht \& Ben-Zeev, 2000; Shih, Pittinsky, \& Ambady, 1999) and domain-identification levels (Aronson et al., 1999; Cadinu, Maass, Frigerio, Impagliazzo, \& Latinotti, 2003; Keller, 2007; Leyens, Desert, Croizet, \& Darcis, 2000; Spencer et al., 1999; Steele, 1997; Stone, Lynch, Sjomeling, \& Darley, 1999) can augment (indicated by dotted lines) negative stereotype threat performance effects. Additionally, diagnostic standardized testing situations have been enough to evoke negative stereotype threat performance effects in stigmatized populations (Croizet \& Claire, 1998; Gonzales, Blanton, \& Williams, 2002; McKown \& Weinstein, 2003; Steele \& Aronson, 1995). Experiencing stereotype threat has been linked to orientation towards performance-avoidance achievement goals; a focus on avoiding negative judgments, instead of on mastering the task (Ryan \& Ryan, 2005). Performance-avoidance achievement goals have been directly linked to increased anxiety (Elliot \& McGregor, 1999, 2001; Elliot, McGregor, \& Gable, 1999; McGregor \& Elliot, 2002; Middleton \& Midgley, 1997; Skaalvik, 1997), decreased self-efficacy (Middleton \& Midgley, 1997; Skaalvik, 1997), and subsequent depressed 
Identity-

Salience

\begin{tabular}{|c|c|c|c|c|c|}
\hline $\begin{array}{l}\text { Stereotype } \\
\text { Awareness }\end{array}$ & & & Anxiety & & \\
\hline $\begin{array}{l}\text { Diagnostic } \\
\text { Testing(in } \\
\text { stereo- } \\
\text { typed } \\
\text { domain) }\end{array}$ & $\begin{array}{l}\text { Domain- } \\
\text { Identification }\end{array}$ & $\begin{array}{c}\text { Performance } \\
\text { Avoidance } \\
\text { Achievement } \\
\text { Goal } \\
\text { Orientation }\end{array}$ & $\begin{array}{c}\text { Self- } \\
\text { Efficacy }\end{array}$ & $\begin{array}{c}\text { Test } \\
\text { Performance }\end{array}$ & Opportunity \\
\hline
\end{tabular}

Figure 1. Mechanisms that may moderate and mediate stereotype threat effects.

performance. In this manner, when stereotype-aware African American children take a standardized test presented as diagnostic of ability, it could be reasonably hypothesized that they will experience increased anxiety and decreased self-efficacy, accompanied by depressed test performance. Prior to this study it could also be reasonably hypothesized that students who are more domain-identified would experience augmented effects. Additionally, through qualitative investigation, more was discovered about the relevant experiences of these children as they navigated the school year approaching the standardized test.

Also guiding the research was the premise that critical race theory can help illuminate the real-life detrimental effects of implicit racial stereotyping. Stereotype 
awareness is a prerequisite for the racial salience that evokes stereotype threat effects, and children from stigmatized groups (e.g., African Americans) are more likely to be aware of stereotypes at a younger age (McKown \& Weinstein, 2003). Since racial stereotypes promote stereotype threat effects and depress standardized test performance, they are directly limiting future opportunity of African Americans. This research adopted an anti-deficit lens with the hope of helping to expose the racism inherent in this status quo by recognizing the importance of including in research the experiential knowledge of oppressed groups.

\section{Rationale}

Standardized testing has become increasingly important at elementary levels and grade promotion is highly contingent upon test performance (U.S. Department of Education, 2007). Therefore, it was of relevant interest to determine what conditions are prerequisite for African American children to experience stereotype threat, and what disruptive processes induced by stereotype threat negatively influence their standardized test performance. This information will provide elementary educators with the means to intervene in an effort to mitigate the maladaptive performance of their students that may be influenced in part by negative societal stereotypes. Positive intervention has already been demonstrated in college populations (Aronson et al., 2002; Martens, Johns, Greenberg, \& Schimel, 2006; Marx \& Roman, 2002) and middle school populations (Cohen et al., 2006; Good et al., 2003; Huguet \& Regner, 2007).

\section{Assumptions}

The researcher makes the following assumptions: (a) Stereotype threat is a real phenomenon. (b) The students will be honest in their responses to the researcher and will 
accurately report their stereotype awareness and level of domain-identification with reading.

\section{Delimitations}

The participants were limited to African American third, fourth, and fifth grade public school students in an urban elementary school in a major metropolitan area in South Florida. The variables in the quantitative phase of the study were delimited to stereotype-awareness, domain-identification, anxiety, goal orientation, and self-efficacy. Furthermore, although the demographics of the school site were similar to those in other urban centers in the United States, participant experiences may represent or reflect a unique experience that may not be generalizable to other settings. The study was delimited in that it was based on the interpretations of one researcher with inherent biases, although every attempt was made to account for the biases through meticulous quantitative and qualitative analyses.

\section{Definitions of Terms}

The following are the definition of terms used for this research:

Stereotype awareness. Refers to whether or not participants are aware of the stereotype of African American intellectual inferiority. Following the open-ended approach (Biek, 2006; McKown \& Weinstein, 2003), a written measure was developed that asks participants how a planet where green people did not think blue people were smart was like the real world (see Appendix A). Participants were scored as being stereotype-aware if their answer referenced racial prejudice, racial discrimination, or racial conflict. Participants were considered not stereotype-aware if none of these was referenced. 
Domain-identification. Refers to the level which participants tie their identity to a particular performance domain, in the case of this study, reading. The English subsection of the Domain Identification Measure (Smith \& White, 2001) was administered to the participants (the word "Reading" was substituted for "English" on the scale to correspond with course nomenclature). Domain-identification was measured with 7 Likert-like survey items related to how good the participants are at reading, as well as to the importance the participants place on reading. These are two crucial aspects of domainidentification as proposed in the conceptualization introduced by Steele (1997).

Diagnosticity. Refers to whether or not a performance task is perceived as diagnostic of intelligence. In the study, participants in diagnostic conditions were told they were completing a reading assessment to see what they were "good at," whereas participants in nondiagnostic conditions were told they were completing the assessment to see "how children solve problems."

Pre-test anxiety. Refers to how anxious participants feel immediately before taking a reading assessment. Self-reported anxiety was measured for all participants using the State Anxiety Scale from State Trait Anxiety Inventory for Children (STAIC) (Spielberger, Edwards, Montouri, \& Lushene, 1973). The STAIC has been widely used to assess anxiety in children. The measure is easy to read and can be administered verbally to younger children, or those with below-average reading abilities. Individuals respond to each item on a three-point rating scale, checking one of three alternatives that describes him or her best or indicates frequency of occurrence. 
Self-efficacy. Refers to participant beliefs about their own abilities. Self-efficacy was measured for all participants using the academic self-efficacy component of the Patterns of Adaptive Learning Scales (PALS) (Midgley et al., 1996).

Orientation towards a performance-avoidance achievement goal. Refers to a focus on avoiding negative judgments, rather than on performing well. Goal orientation of participants was measured using the performance-avoid goal orientation (revised) component of the PALS (Midgley et al., 2000).

\section{Overview of Chapters}

In this chapter the researcher has explained the background of the study, described the purpose of the study, and posed the research questions, rationale, and hypotheses for the study. In addition, chapter 1 provided a conceptual model laying out a theoretical framework for stereotype threat, and included a description of the assumptions and delimitations of the study. Included in chapter 2 is an explication and critique of the literature related to the research questions. In chapter 3, the researcher provided a detailed description of the sequential quantitative-qualitative design and the methods used to address the research questions. The researcher presents the comprehensive results of the data analysis related to the research questions in chapter 4 . In chapter 5, the researcher includes a summary of the study, an overview of significant findings, an evaluation of findings with respect to prior research, a discussion of the limitations, and a discussion of implications for practice, policy, and research. 


\section{CHAPTER II}

\section{REVIEW OF LITERATURE}

The standardized test performance of African American students is a serious concern and source of debate (Herrnstein \& Murray, 1994; Jencks \& Phillips, 1998; Thernstrom \& Thernstrom, 2003). Each year, statistics from statewide and national testing programs reiterate a troubling pattern of comparative underperformance; there is a reliable test score gap between White and African American students at every grade level (College Board, 2006; Florida Department of Education, 2006a; NCES, 2007). Stereotyping may play a role in this disparity. When prevailing stereotypes about the intellectual and cognitive abilities of African Americans are made salient, their academic performance is depressed (Blascovich, Spencer, Quinn, \& Steele, 2001; Massey \& Fischer, 2005; McKay, Doverspike, Bowen-Hilton, \& Martin, 2002; McKown \& Weinstein, 2003; Steele, 1997; Steele \& Aronson, 1995). Results indicate that racial performance gaps may be in part a product of both contextual and cognitive processes amenable to intervention. A deeper understanding of these processes is necessary, especially at the elementary school level.

The first section of this review of literature examines research related to stereotype threat. This section begins with a review of research related to children, then it delineates mediating factors of stereotype threat including a relationship to achievement goal theory. The second section of this review of literature examines critical race theory in education in order to further define an anti-deficit theoretical lens for African American academic performance. Combined, these sections will provide relevant background for the dissertation research. 


\section{Stereotype Threat}

Stereotype threat (Steele \& Aronson, 1995) refers to the risk of confirming a negative stereotype about one's group in a particular performance domain. Stereotype threat theory posits that prevailing negative stereotypes about the abilities of certain groups, made salient for individuals who belong to those groups, triggers underperformance. The possibility of confirming negative performance stereotypes becomes salient either when primed, or when tasks are framed as diagnostic of ability. Negative performance effects related to stereotype threat have also been demonstrated for several different populations, in a variety of performance domains. Table 1 displays notable examples.

\section{Stereotype Threat Research Related to Children}

There are a limited number of studies that have examined the stereotype threat performance effects on young children (e.g. Ambady, Shih, Kim, \& Pittinsky, 2001; Huguet \& Regner, 2007; McKown \& Weinstein, 2003). Ambady et al. suggested that as early as the lower elementary grades children show shifts in performance associated with the activation of positive and negative stereotypes. The subtle activation of racial identity generally facilitated the mathematics test performance of Asian girls, whereas the subtle activation of gender identity generally impeded mathematics performance.

McKown and Weinstein (2003) demonstrated that stereotype threat also negatively affects the performance of stigmatized groups without explicit stereotype activation. Their research suggested that young children from academically stigmatized ethnic groups (e.g., African Americans) are likely to be aware of academic stereotypes, and that diagnostic testing conditions lead to stereotype threat effects for these groups. 
Table 1

Research Suggesting that Stereotype Threatening Situations Depress Performance

\begin{tabular}{llll}
\hline Population & $\begin{array}{c}\text { Performance } \\
\text { Domain }\end{array}$ & \multicolumn{1}{c}{ Result } & Citation \\
\hline African & Standardized & African American college & (Blascovich et \\
Americans & Test & $\begin{array}{l}\text { White college students only } \\
\text { when the test was described as } \\
\text { diagnostic of abilities. }\end{array}$ & $\begin{array}{l}\text { 2001; Steele \& } \\
\text { Aronson, 1995) }\end{array}$ \\
& & African American college & (McKay et al., \\
& & students performed worse than & 2002) \\
African & IQ Test & White college students only & \\
Americans & & when the test was described as & \\
& & diagnostic of intelligence. &
\end{tabular}

\begin{tabular}{|c|c|c|c|}
\hline Women & $\begin{array}{l}\text { Standardized } \\
\text { Math Test }\end{array}$ & $\begin{array}{l}\text { Female college students } \\
\text { performed worse than male } \\
\text { college students only when the } \\
\text { test was described as producing } \\
\text { gender differences. }\end{array}$ & $\begin{array}{l}\text { (Keller, 2007; } \\
\text { Lesko \& Corpus, } \\
\text { 2006; Spencer et } \\
\text { al., 1999) }\end{array}$ \\
\hline Latinos & $\begin{array}{l}\text { Standardized } \\
\text { Math Test }\end{array}$ & $\begin{array}{l}\text { Latino college students } \\
\text { performed worse than White } \\
\text { college students only when the } \\
\text { test was described as diagnostic } \\
\text { of abilities. }\end{array}$ & $\begin{array}{l}\text { (Gonzales et al., } \\
2002 \text { ) }\end{array}$ \\
\hline Low-Income & $\begin{array}{l}\text { Standardized } \\
\text { Test }\end{array}$ & $\begin{array}{l}\text { Low-income college students } \\
\text { performed worse than high- } \\
\text { income college students only } \\
\text { when the test was described as } \\
\text { diagnostic of abilities. }\end{array}$ & $\begin{array}{l}\text { (Croizet \& Claire, } \\
\text { 1998; Harrison, } \\
\text { Stevens, Monty, \& } \\
\text { Coakley, 2006) }\end{array}$ \\
\hline Whites & $\begin{array}{l}\text { Standardized } \\
\text { Math Test }\end{array}$ & $\begin{array}{l}\text { White male performance on a } \\
\text { difficult math test was } \\
\text { depressed by invoking a } \\
\text { comparison with Asians. }\end{array}$ & $\begin{array}{l}\text { (Aronson et al., } \\
1999)\end{array}$ \\
\hline Whites & Athletic Ability & $\begin{array}{l}\text { White males performed worse } \\
\text { when a golf task was } \\
\text { characterized as diagnostic of } \\
\text { natural athletic ability. }\end{array}$ & (Stone et al., 1999) \\
\hline
\end{tabular}


Their study utilized a 2 (threat condition) x 2 (stereotype status) factorial design typical of stereotype threat research. Students from stigmatized ethnic groups performed worse on a reading performance task than students from nonstigmatized groups, only when the test was characterized as diagnostic of ability. Huguet and Regner (2007) replicated these findings for young girls and mathematics. Although more research on the effects of stereotype threat on children is needed, the existing evidence suggests that children are prone to the same stereotype threat effects as older populations.

\section{Domain-Identification}

A negative stereotype is most threatening when the performance domain is selfrelevant for the individual (Aronson et al., 1999; Cadinu et al., 2003; Keller, 2007; Leyens et al., 2000; Spencer et al., 1999; Stone et al., 1999). Specifically, Aronson et al. (1999, Study 2) utilized a 2 (threat condition) x 2 (domain-identification) factorial design to demonstrate that participants who highly identified with their math performance performed less well on a mathematics test when a negative stereotype pertaining to their group was activated than when the stereotype was not activated. This was not true for participants who reported a lower level of identification with their math performance. Thus, it is when a student ties his or her identity to his or her performance on a standardized test that a negative stereotype is most threatening and influential of performance. Threatening situational pressure thus has greater effect on a subset of the stereotyped group that places higher importance on the standardized test results. In such cases, students who are domain-identified (Steele, 1997) will not only have traditional testing concerns, but also the added pressure of not confirming a prevailing stereotype about their group. That is, if students identify with the standardized testing domain, the 
prospect of being viewed stereotypically may be upsetting and disturbing, resulting in a deleterious effect on their performance.

High performing college students are likely to be domain-identified with standardized testing in that they understand that their performance on standardized tests is important for their academic future, and their academic future is important to them (Steele, 1997). A high-stakes evaluative environment makes salient African American college students' social identity and relevant stereotypes (Steele \& Aronson, 1995). Presently, the No Child Left Behind Act (NCLB) of 2002 emphasizes standardized testing in elementary grades (U.S. Department of Education, 2007). As a result, young children are made acutely aware of standardized test significance at an earlier age and have a heightened investment in high performance on such tests, as low performance may result in retention - an undesirable result (Jimerson, Ferguson, Whipple, Anderson, \& Dalton, 2002; Shepard \& Smith, 1989). Many students at urban elementary schools tie their identity to their standardized test scores (Kozol, 2005). Therefore, there is a pressing need for research on how the standardized test performance of young children is presently influenced by the situational pressures outlined by stereotype threat, especially as it relates to level of domain-identification.

However, it must be noted that past researchers have not been in agreement on what should be used to measure domain-identification. Researchers have done so using SAT scores, grades, choice of classes, or self-developed questions. For example, Aronson et al. (1999) utilized two questions assessing perceived math ability and importance and SAT scores, whereas Spencer et al. (1999) used a combination of SAT scores, course selection, and 2 Likert-scale questions. This assortment of measures makes the 
development of a solid definition of domain-identification difficult. For this purpose Smith \& White (2001), developed "a consistent method for assessing domain identification that should work for any population" (p. 1042), the Domain Identification Measure (DIM).

A response to continued stereotype threatening experiences in a domain may be eventual disidentification from said domain (Major, Spencer, Schmader, Wolfe, \& Crocker, 1998; Steele, 1997; Wong, Eccles, \& Sameroff, 2003). Specifically, this could translate to the disidentification of African American children from areas which they are negatively stereotyped (e.g. academics), and their subsequent underperformance in relation to non-stereotyped groups (Wong et al.). Because domain-identification has been demonstrated to influence stereotype threat effects (Aronson et al., 1999), disidentification is possibly a way to avoid some of the deleterious effects of stereotype threat. Supporting this theory of eventual disengagement from the academic domain among stereotype-threatened students, Osborne (1997) found a weaker relationship between academic performance and self-esteem among African American junior high school students than among White junior high school students. According to his research, African American students invest less of their self-worth in academic performance than White students. Ogbu (1986) reported that similar academic performance gaps exist between the stereotyped groups throughout the world and the non-stereotyped members of their society as exists between African Americans and White Americans.

The theory of stereotype threat as it relates to domain-identification assumes that school success requires a level of identification with academic performance and relevant 
sub-domains; it also assumes that in specific domains where certain groups are negatively stereotyped, those who are domain-identified face augmented stereotype threat performance effects (Steele, 1997). Stereotype threat most significantly depresses the standardized test performance of women and African Americans who are most highly identified with the tested performance domain (Spencer et al., 1999; Steele \& Aronson, 1995).

\section{Stereotype Awareness}

The majority of all children are aware of common societal stereotypes by the age of 10, and children from academically stigmatized groups (e.g., African Americans) are significantly more likely to be aware of academic stereotypes than those from nonstigmatized groups (e.g., Whites) (McKown \& Weinstein, 2003, Study 1). In terms of stereotype threat, this suggests that the stereotype of African American intellectual inferiority is threatening at young ages. Specifically, African American children aware of broadly held stereotypes experience stereotype threat effects when subjected to diagnostic testing (McKown \& Weinstein, 2003, Study 2). NCLB has mandated strict protocols of standardized test practice especially in schools housing predominantly African American populations (Ahlquist, 2003; Kozol, 2005). Negative stereotypes associated with the test performance of African American children are thus made increasingly salient to even the youngest students in these schools. When a negative stereotype is activated, deleterious stereotype threat effects have been demonstrated as early as the kindergarten level (Ambady et al., 2001).

In terms of stereotype threat, awareness of negative societal stereotypes about one's group may lead to distracting thoughts about confirming said stereotype, and these 
thoughts may in turn lead to the very failure that is feared. This is explained vividly in an example by Jordan and Lovett (2007):

For example, a girl who tries out for an improvisational comedy troupe in high school, aware of a stereotype that women do not make good comedians, may find herself flustered and unable to perform to her potential. She may, furthermore, attribute her comedic stumbles to her femaleness and become dejected in a way that male members of her troupe do not when they experience frustration. (p. 46)

Additionally, research has suggested that stereotype awareness may be enhanced by media images (Rivadeneyra, 2006), or simply the presence of participants from outside of the stereotyped group (Sloan et al., 2003).

\section{Social Identity Salience}

Stereotype threat among stigmatized groups may also be moderated by the salience of one's racial or social identity. When a particular identity of an individual is directly made salient, his or her performance alters in the direction of associated relevant stereotypes (Shih et al., 1999). Additionally, Inzlicht and Ben-Zeev (2000) have shown that if the stereotype is a negative one, the more that a member of the stigmatized group is singled-out, the worse their performance. Specifically, Steele and Aronson (1995, Study 3) have demonstrated that diagnostic testing situations increase the racial salience of African Americans. Participants in a diagnostic group were significantly more likely to fill in the blanks of incomplete words with race-related vocabulary (i.e., RACE for CE) than were participants in a nondiagnostic condition.

Stereotype threat may be related to the distancing of oneself from a stereotyped social identity. For example, African American students in a diagnostic testing condition were less likely to report liking stereotypically African American items, such as hip-hop 
and basketball, than African American students in a nondiagnostic condition; and only $25 \%$ of African Americans in a diagnostic condition were willing to indicate their race on a post-test questionnaire, as compared to $100 \%$ in a nondiagnostic condition (Steele \& Aronson, 1995, Study 3). Eventually, some students who do well in their academic efforts may feel pressured to abandon their African American identity (see Fordham \& Ogbu, 1986). At the same time, however, Davis, Aronson, and Salinas (2006) have suggested that African Americans who have achieved an inner security and selfconfidence with being Black are less susceptible to negative stereotype threat effects. Additionally, under diagnostic conditions, a high level of consciousness of one's stereotyped identity augments negative stereotype threat performance effects (Brown \& Pinel, 2003).

Stereotype Threat Related to Achievement Goal Theory

Achievement goal theory addresses the reasons students attribute to their achievement behaviors (see Dweck, 1986). Achievement goals refer to beliefs about purpose, ability, and probability of success that influence one's attitude towards and engagement in a task (Dweck \& Leggett, 1988). Pintrich (2000) described achievement goals as the reasons why one engages in a particular behavior. There are two broad types of achievement goals. A mastery goal concerns a focus on evaluating proficiency by whether a task has been mastered, or skills have been completely developed (Ames, 1992), and a performance goal concerns a focus on normative standards where one's proficiency is evaluated regarding how well one has done compared to others (Elliot \& McGregor, 2001). However, not all achievement goals are directed towards reaching a 
desirable result; goals can also be directed towards avoiding an undesirable result (Elliot \& Sheldon, 1997).

Stereotype threat focuses threatened individuals on avoiding negative judgments about their ability in a particular performance domain (Steele, 1997). In achievement goal theory, a focus on avoiding negative judgments is characterized as a specific type of performance goal referred to as a performance-avoidance goal (Elliot \& McGregor, 2001). A performance-avoidance goal has been shown to be a positive predictor of cognitive disorganization, and a negative predictor of exam performance (Elliot et al., 1999; Middleton \& Midgley, 1997). Ryan and Ryan (2005) have suggested a relationship between stereotype threat and achievement goals based on mediators including increased anxiety and decreased self-efficacy.

Anxiety. Some research has found no association between stereotype threat and self-reported test anxiety (Aronson et al., 1999; Gonzales et al., 2002; Keller \& Dauenheimer, 2003; Schmader, 2002), whereas other research suggests than when students experience stereotype threat, they report increased anxiety (Ford, Ferguson, Brooks, \& Hagadone, 2004; Inzlicht \& Ben-Zeev, 2003; Osborne, 2001; Spencer et al., 1999; Steele \& Aronson, 1995; Stone et al., 1999). However, stereotype-threatened individuals do not always present their expressed anxiety in self-reports (Bosson, Haymovitz, \& Pinel, 2004). Instead, physiological evidence indicates that anxiety has a role as a mediator of stereotype threat performance effects. For example: (a) Blasovich et al. (2001) demonstrated that African American participants in a stereotype threat condition exhibited a significant increase in blood pressure, whereas the blood pressure of African Americans in a nondiagnostic condition decreased, (b) Croizet et al. (2004) 
demonstrated that heart-rate increased for African American participants in a diagnostic condition, and (c) Bosson et al. (2004) demonstrated that observer-reported anxiety, as opposed to self-reported anxiety, is a significant mediator of stereotype threat performance effects.

The possibility of being judged according to a prevailing stereotype during a standardized test likely leads to anxiety regarding performance evaluation and subsequent decreased test performance. In relation to achievement goal theory, this situation frames a stereotyped test-taker's goal as performance-avoidance; a focus on avoiding negative judgments, instead of on mastering the task. Performance-avoidance goals have been directly linked to increased anxiety and lower levels of performance (Elliot \& McGregor, 1999, 2001; Elliot et al., 1999; McGregor \& Elliot, 2002; Middleton \& Midgley, 1997; Skaalvik, 1997). Ryan and Ryan (2005) suggested a model in which the situational cues that initiate stereotype threat orient an individual towards a performance-avoidance achievement goal, leading to increased test anxiety and diminished performance. Given the stereotype awareness of African American children (McKown \& Weinstein, 2003) and the increasing importance of standardized testing at the elementary level (U. S. Department of Education, 2007), it is possible that when African Americans experience stereotype threat in a standardized testing situation, they may orient themselves towards a performance-avoidance achievement goal, which may lead to increased anxiety and depressed performance.

Self-efficacy. Stereotype threatening situations may introduce negative stereotypical thoughts which individuals must contend with during performance (Steele, 1997). Thus, stereotype threat may not instantly influence self-efficacy (one's beliefs 
about their own abilities), but rather set up an interpretive framework (Steele) for continuous self-evaluation, so that when difficulty is experienced, self-efficacy falters, and performance is depressed. A relationship has been established between stereotype threat and decreased self-efficacy (Inzlicht, McKay, \& Aronson, 2006; Steele \& Aronson, 1995, Study 4), and has been shown to lead to feelings of dejection (Keller \& Dauenheimer, 2003).

Stereotype threat has been also shown to cause self-doubt immediately prior to an exam (Cadinu et al., 2003; Spencer et al., 1999; Stangor, Carr, \& Kiang, 1998; Steele \& Aronson, 1995). Additionally, the self-efficacy of African Americans falters in stereotype-threatening situations where they are a distinct minority (Milner \& Hoy, 2003). However, research has also suggested that stereotype threatening situations do not affect general academic self-efficacy (Aronson, Quinn, \& Spencer, 1998; Shih et al., 1999; Steele \& Aronson, 1995), and is not therefore related to a "self-fulfilling prophecy." Again, self-report measures may not be the best way to measure the mediating processes of stereotype threat, especially if mediating processes are occurring at the unconscious level (see Croizet \& Claire, 1998). The self-efficacy beliefs of children in relation to stereotype threat require further research.

In relation to achievement goal theory, however, results have indicated that one's self-efficacy beliefs in respect to performance on a particular task are situational and malleable (Betz \& Hackett, 1983; Bong \& Skaalvik, 2003). When one is oriented towards a performance-avoidance goal, research has clearly suggested that self-efficacy is decreased (Middleton \& Midgley, 1997; Skaalvik, 1997). If stereotype threat leads to a performance-avoidance achievement goal orientation during a testing situation, African 
American students are likely to be concerned that this might indicate low ability, undermining their self-efficacy (Ryan \& Ryan, 2005). Again, given the stereotype awareness of African American children (McKown \& Weinstein, 2003) and the increased importance of standardized testing at the elementary level (U. S. Department of Education, 2007), African American children may experience similar stereotype threat effects. However, additional qualitative analyses may be needed to sharpen and broaden our knowledge of stereotype threat, as the current quantitative measures of potential mediating factors of stereotype threat (e.g. self-efficacy) fail to capture some of the issues exemplified by qualitative investigation (e.g. Milner \& Hoy, 2003).

\section{Intervention}

The ubiquity of stereotype threat performance effects has prompted research that has investigated the success of a variety of interventions in an effort to mitigate the negative effects. Reframing the performance task as nondiagnostic (Blascovich et al., 2001; Croizet \& Claire, 1998; Gonzales et al., 2002; Harrison et al., 2006; McKay et al., 2002; McKown \& Weinstein, 2003; Steele \& Aronson, 1995; Stone et al., 1999), or as gender-fair (Keller, 2007; Lesko \& Corpus, 2006; Spencer et al., 1999) has mitigated negative effects in experimental conditions, however such recharacterization is not always practical in a real-world setting.

At the college level, successful interventions have increased the academic performance of stereotyped populations by teaching students to view intelligence as malleable rather than fixed (Aronson et al., 2002). The positive effects of this intervention has been replicated at the middle-school level (Good et al., 2003). Beyond specific successful intervention for stereotype-threatened students, viewing intelligence 
as malleable is associated with general high academic achievement for all students (Stipek \& Gralinski, 1996). Intervention research having students reaffirm their sense of self-worth has also been successful in mitigating stereotype threat effects at the college (Frantz, Cuddy, Burnett, Ray, \& Hart, 2004; Martens et al., 2006), and middle-school (Cohen et al., 2006) levels. Additionally, research has suggested that increased accessibility to positive in-group role models can mitigate negative stereotype threat effects for females in the mathematics domain at the college (Marx \& Roman, 2002), and middle-school (Huguet \& Regner, 2007) levels. Such intervention demonstrates that stereotype threat is as much a contextual issue, as it is a psychological issue. Future research in an elementary school setting examining the effects of such intervention on academic performance is therefore critical.

With older stereotyped students, additional intervention techniques have also been successful. For example, simply discussing stereotype threat may help to ameliorate negative performance effects. Johns, Schmader, and Martens (2005) have suggested that such intervention allows students to attribute anxiety to this outside source, thereby assuaging test-related anxiety, and improving the academic performance of stereotypethreatened students. Even a brief intervention that identifies members of stigmatized groups who have succeeded despite a stereotype-threatening environment has been suggested to reduce anxiety and increase the test performance of stigmatized groups (McIntyre, Paulson, \& Lord, 2003). Additionally, invoking measurement criteria of "high standards," and assuring college students that they can meet these standards, makes participants less likely to believe they are being viewed stereotypically, thus reducing stereotype threat performance effects (Cohen, Steele, \& Ross, 1999). 
Rosenthal and Crisp (2006) have suggested that having college students think about overlapping characteristics, thereby blurring intergroup boundaries, mitigates stereotype threat performance effects . Also, prompting female students to focus on their individual characteristics, as opposed to group characteristics, protected them from stereotype threat activation in the mathematics domain (Ambady, Paik, Steele, OwenSmith, \& Mitchell, 2004). Additionally, emphasizing the social instead of the genetic basis for stereotypes may buffer individuals from stereotype threat effects (Dar-Nimrod \& Heine, 2006; Shih, Bonam, Sanchez, \& Peck, 2007). In sum, different threats to different populations may be experienced differently, and therefore may require different interventions to mitigate effects (Shapiro \& Neuberg, 2007).

\section{Critical Race Theory in Education}

Critical race theory in education (CRT) is derived from critical legal studies (see Tate [1997] for a review). Critical race theory in law repositions race as the primary lens for exploring legislation. Within the past decade or so, researchers have applied critical race theory to educational issues (Ladson-Billings, 1999b; Ladson-Billings \& Tate, 1995; Solorzano, 1998; Solorzano, Ceja, \& Yosso, 2000). CRT is defined as a theoretical framework that counters the dominant dialogue on race as it relates to education by examining how educational praxis and policy subordinates certain racial groups (Delgado Bernal, 2002; Solorzano \& Yosso, 2001), and establishes the experiences of the dominant group as the norm (Duncan, 2002a). CRT is described as an appropriate lens for qualitative research in the field of education (Delgado Bernal). Critical qualitative researchers utilize CRT to "examine the impact of race and racism along the entire 
educational pipeline from elementary schools, through middle and high schools, and on to the university" (Lynn \& Adams, 2002, p. 89).

CRT has provided an alternative theoretical framework through which to conduct qualitative research in education by differentiating between the dominant discourse and the experiential knowledge of people of color (Duncan, 2002b). The research has demonstrated that by utilizing a counter-storytelling method, researchers can incorporate the perspectives of people of color (DeCuir \& Dixson, 2004; Solorzano \& Yosso, 2002). Critical race theorists have suggested that the dominant discourse of "equal opportunity" has made it more difficult for people of color to define their own realities (Parker, Deyhle, \& Villenas, 1999). CRT maintains that in this manner, racist practices are infused within the educational system (Lopez, 2003). As a response, researchers have sought the voices of people of color to develop counter-stories to a dominant discourse where African American students are often viewed as problems to be controlled, both educationally and behaviorally (see Ginwright, Cammarota, \& Noguera, 2005; Parker \& Stovall, 2004; Saltman \& Gabbard, 2003).

CRT researchers view deficit approaches to understanding racial differences (e.g. Herrnstein \& Murray, 1994; Thernstrom \& Thernstrom, 2003) as discriminatory. Nasir and Hand (2006) have delineated how these traditional approaches have sought to explain the racial gap in test performance with both biological and cultural factors. In this manner, standardized testing has lead to the negative stigmatization of African American students, and to their lack of access to the best educational programs (see Noguera, 1996). Critical race theorists have suggested that the standardized testing movement has been "a movement to legitimize [the notion of] African American students' deficiency 
under the guise of scientific rationalism" (Ladson-Billings, 1999a, p. 23). Research has suggested that the subsequent overrepresentation of African American students in remedial classes reinforces negative racial stereotypes of intelligence (Noguera, 2003). CRT provides a tool for researchers to investigate how such racial stereotypes function to influence school climate and student performance (Solorzano \& Yosso, 2001; Villenas \& Deyhle, 1999). This can be directly related to investigating influences of stereotype threat (Steele, 1997); the risk of confirming negative stereotypes about one's group. CRT can be utilized as a lens through which to connect research to practice, and move towards positive change (Parker \& Lynn, 2002). Research seeking the voices of students affected by stereotype threatening environments is lacking, and necessary for this change to occur.

Solorzano (1998) defines five themes of CRT in education: (a) the centrality and intersection of race and racism, (b) the challenge to dominant ideology, (c) the commitment to social justice, (d) the centrality of experiential knowledge, and (e) the interdisciplinary perspective. The effects of stereotype threat can be viewed through these five themes.

\section{The Centrality and Intersection of Race and Racism}

Critical race theorists recognize how conceptions of fairness, meritocracy, and objectivity have been historically utilized to subordinate and marginalize students of color (Solorzano \& Yosso, 2001). NCLB and the subsequent national implementation of high-stakes testing regimens may be serving to further this historic trend. Federal law mandates changes for schools deemed "in need of improvement" based on standardized test scores (U. S. Department of Education, 2007). These penalties force a narrow focus on test practice in schools educating large populations of African American children 
(Johnson, Kardos, Kauffman, Liu, \& Donaldson, 2004; Kozol, 2005). These changes also have inherent negative effects on both the performance and attitudes of affected teachers, including dissatisfaction with curricular materials, and lowered beliefs in the abilities of students (Crawford, 2004; Kauffman, Johnson, Kardos, Liu, \& Peske, 2002). Such state mandated curricula highlight an undercurrent of racism and classism that reinforces educational inequity in United States public schools.

Students are also affected by this mandated focus on testing. Stereotype threat research has consistently demonstrated that increased importance of diagnostic testing heightens stereotype salience, which depresses the performance of students from what NCLB calls low-performing "subgroups" (McKown \& Weinstein, 2003; Steele \& Aronson, 1995). These facts begin to illuminate a frightening cycle, in which standardized testing and subsequent prescribed curriculum may be serving to perpetuate educational inequities, and maintain an unbalanced status quo. Research investigating the perspectives of affected students is important. Solorzano, Ceja, and Yosso (2000) used a critical race framework to examine how racial climate impacts the undergraduate experiences of African American students arguing specifically through the lens of stereotype threat and high-stakes testing. The researchers suggested that the prospect of conforming to a negative stereotype about African Americans might be enough to undermine an African American college student's performance and achievement and thereby negatively contribute to the collegiate racial climate at his or her institution of higher learning. Research is necessary to examine the relationship between stereotype threat and school climate at the elementary and secondary levels. This is especially important in that Wong et al. (2003) has suggested that perceived experiences of racial 
discrimination at school from one's teachers and peers predicts declines in grades, academic self-concept, academic domain-identification, and mental health.

\section{The Challenge to Dominant Ideology}

Critical race theorists challenge dominant social and cultural assumptions regarding intelligence and capabilities through research and pedagogy (Solorzano \& Yosso, 2001). Viewed through a CRT lens, stereotype threat research challenges the dominant ideology, which supports a deficit discourse about students of color where racial stereotypes are based on deficit models (e.g. Herrnstein \& Murray, 1994; Thernstrom \& Thernstrom, 2003). CRT advocates for research on the racial standardized test score gap to move from a discourse of "deficiency" and to a discourse of achievement (see Stinson, 2006). Deficit models justify certain educational policies detrimental to students of color (see Meier \& Wood, 2004). For example, Crawford (2004) has suggested that the negative stereotype associating intellectual inferiority with African Americans normalizes the performance gap associated with standardized testing, and creates a frightening cycle of low expectations. Potentially, this sets up a hegemonic

educational system where minority students fail because schools reinforce and reproduce social inequalities and stereotypes.

When prevailing stereotypes about the intellectual and cognitive abilities of certain groups are made salient for individuals who belong to those groups, it leads to lower performance (Ambady et al., 2001; Shih et al., 1999; Spencer et al., 1999; Steele \& Aronson, 1995). Importantly, this demonstrates that racial performance gaps are at least in part a product of both contextual and cognitive processes that may be amenable to intervention, which disrupts the dominant ideology of a deficit model. This is of 
importance in that standardized testing in the United States is becoming an increasingly determinant factor in children's educational futures at younger ages. The voices of these students are an integral factor in furthering research towards positive solutions.

\section{The Commitment to Social Justice}

Critical race theorists support a research agenda that offers revolutionary responses to oppression and empowers marginalized groups (Dixson \& Rousseau, 2006). The racial test score gap manifestly ensures increased inequality in that low-performing schools may be mandated to impose test-based curricula (U. S. Department of Education, 2007). Presently, in response solely to test-scores, which are influenced by societal stereotypes perpetuated by privileged groups (Steele, 1997, 2003; Steele \& Aronson, 1995), African American students from low-income backgrounds are likely being instructed using curricula based heavily on rote techniques and test practice (Ahlquist, 2003; Kozol, 2005). Additionally, Costigan, Zumwalt, Crocco, and Gerwin (2004) report that many teachers and administrators responsible for educating this population report high levels of discouragement, lack of positive reinforcement, lack of autonomy, and are likely looking to teach elsewhere. On the other hand, concentrations of high-achieving students in high-achieving schools, are likely taught by teachers and administrators reporting high levels of job satisfaction (Saltman \& Gabbard, 2003). Such "confections of apartheid" (Kozol, 2005, p. 87) serve to further deepen the divisions of society, and can be seen as oppressive through a CRT lens.

Stereotype threat research is at a stage where interventions have been implemented that have significantly improved exam performance (e.g. Good et al., 2003). The perceptions of students are necessary components to enhancing these intervention 
techniques. In the present era where standardized tests have become increasingly

determinant of educational experiences, expanding such research to the elementary level can serve as a revolutionary response to the perpetual educational marginalization of students of color in the United States, and part of a struggle for social justice.

\section{The Centrality of Experiential Knowledge}

Critical race theorists recognize the importance of the narratives and experiential knowledge of marginalized peoples, advocating the use of counter-storytelling (Solorzano \& Yosso, 2002). Perry (2003) examined how contemporary school settings undermine African American student achievement. She addressed the following integral questions:

Why should one make an effort to excel in school if one cannot predict when and under what circumstances learning will be valued, seen, acknowledged? [and] Why should one focus on learning in school if that learning doesn't, in reality... have the capacity to affect, inform, or alter one's self perception or one's status as a member of an oppressed group? (p. 11)

She utilized the counter-stories of eight African Americans, including Frederick Douglas, Malcolm X, and Joycelyn Elders, to demonstrate the African American philosophy of schooling. The common elements that tie the narratives together are that "academic achievement, doing well in school and pursing learning... is always accomplished in the face of considerable constraints" (p. 49). These narratives provide interesting insight on the African American experience, which includes a strong desire for education. This is contrary to societal stereotypes, and the dominant discourse.

Perry (2003) also delineated how the current dialogue is problematic in that it creates a framework that blames the African American community for the underachievement of African American students (see Thernstrom \& Thernstrom, 2003). 
Her use of the experiential knowledge of African Americans offered a critique of Ogbu's (1983) social mobility theory, which contended that the cultural differences attributed to being a member of a racial minority group do not predict school performance. She maintained that, "Ogbu could not have made the assertion that African Americans have not developed an academic tradition if he had known of African Americans' epic historical struggle for literacy and educational opportunity" (p. 62). Here she demonstrates the CRT tenet of the importance of experiential knowledge.

Steele (2003) has suggested that stereotype threat causes increased anxiety for African American students and that performance is less about their ability than it is about "having to perform on a test and in a situation that may be primed to treat them stereotypically" (p. 123). His research has offered three strategies that may help in dealing with stereotype threat: (a) pedagogy and relationship between students and teachers, (b) institutional and contextual changes designed to promote fairness and justice for all groups, and (c) expandable personal theory of intelligence in which one views their intelligence through effort and experiences. Therefore, research that takes into account the personal experiences of stereotyped students is necessary. According to Dixson and Rousseau (2006), a CRT moment occurs when the salience of race is highlighted during normal events. In this respect, the racial test score gap, combined with the increased importance of standardized testing, has made standardized testing situations CRT moments.

\section{The Interdisciplinary Perspective}

Critical race theory challenges the one-sided and unidisciplinary concentration of both traditional and contemporary analyses of educational inequities (Solorzano \& 
Yosso, 2001). Such a concentration only serves to maintain the cultural deficit model, and related racial stereotypes, which remains the apparent theory of choice at many schools (Lopez, 2003). In the past, stereotype threat has largely been examined in the psychological domain. However, looking at stereotype threat through a CRT lens would supplement a theoretical framework to examine the effects of the phenomenon on a wide range of adverse social, educational, and cognitive outcomes for African American children from new perspectives, and help serve to bridge the gap between psychology and critical education. 


\section{CHAPTER III}

\section{METHOD}

The study utilized a mixed method design, combining both quantitative and qualitative approaches. Specifically, a sequential mixed method design (Tashakkori \& Teddlie, 2009, 2003) was implemented in which the quantitative phase of the study was followed by a separate qualitative phase. Methods were mixed for the purpose of complementarity (Greene, 2007). "With this purpose, a mixed methods study seeks broader, deeper, and more comprehensive social understandings by using methods that tap into different facets or dimensions of the same complex phenomenon" (p. 101). The phenomenon being investigated was that of stereotype threat (Steele \& Aronson, 1995); the risk of confirming a negative stereotype about one's group in a particular performance domain. A graphical representation of the sequential mixed method design was derived from Tashakkori and Teddlie (2003, p. 688), and is provided in Figure 2.

In the present study, the quantitative design contains both ex-post facto and experimental comparisons. An ex-post facto comparison was employed to test the hypothesis for research subquestion $2 \mathrm{a}$, which asked whether domain-identification is associated with student performance on a reading assessment. The more and less domainidentified groups are pre-existing. A weakness here is that of common cause, or the possibility that both domain-identification and performance on a reading assessment are both influenced by a third factor. Importantly though, the research question asks only if a relationship exists. When comparing the performance of participants in diagnostic and nondiagnostic conditions, however, experimental manipulations are employed. 
Participants are randomly assigned. These research questions ask of the influence of the diagnostic testing situation.

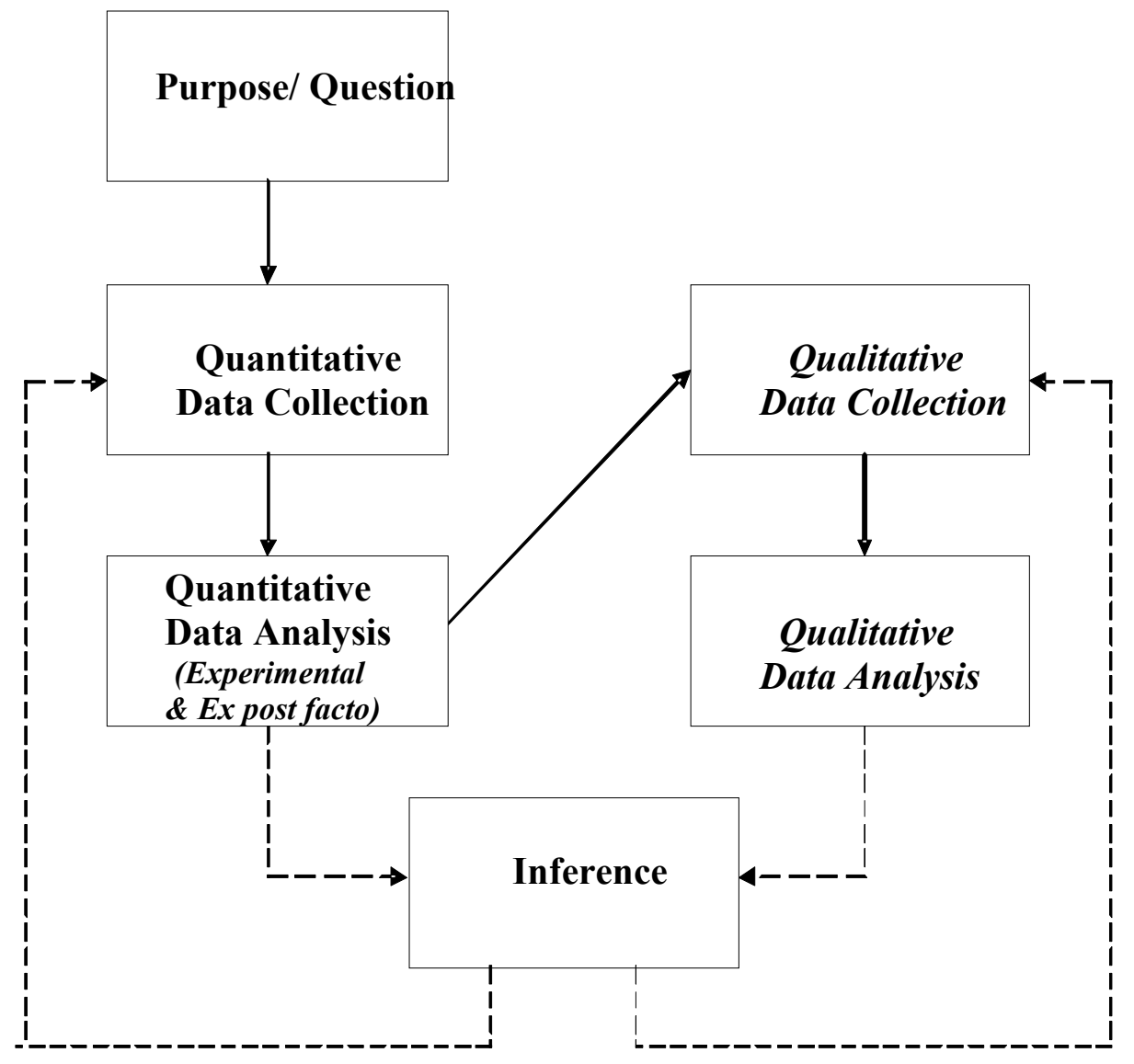

Figure 2. Sequential mixed method design.

\section{Phase 1}

The overarching research question that guided the study was: Are the standardized testing experiences of African American children in an urban elementary school related to their level of stereotype awareness? A specific subquestion was: Is the standardized reading test performance of African American elementary school students related to their awareness of racial stereotypes? Specifically, does a diagnostic situation have an influence on the reading test performance of African American elementary school 
students aware of negative racial stereotypes? The hypothesis used to help answer this research question in Phase 1 was that African American elementary school students who are aware of the societal stereotype of African American intellectual inferiority will significantly underperform on a reading comprehension activity framed as a test diagnostic of intelligence, as compared to when the same activity is framed as nondiagnostic of intelligence.

A second subquestion was: Is level of domain-identification with reading related to the test performance of African American elementary school students? The first hypothesis concerning this research question was that more highly domain-identified students will perform better than less domain-identified students in all conditions regardless of stereotype awareness. The second and more important hypothesis was that stereotype-aware students who are more highly domain-identified with reading will experience more of a comparative underperformance in the diagnostic condition, then students who are less domain-identified. This would suggest that the pressure of diagnostic testing has a more significant negative effect on a subset of the stereotyped group that ties their identity to the reading test results.

In order to explore additional dependent variables of interest, quantitative measures were also administered in each condition to assess test anxiety, self-efficacy, and achievement goal orientation. Hypotheses concerning these variables included: (a) Participants in diagnostic conditions will report higher levels of anxiety, and lower levels of self-efficacy than participants in nondiagnostic conditions, (b) Stereotype-aware participants in diagnostic conditions will report higher levels of anxiety, lower levels of self-efficacy, and be more likely to report a performance-avoidance achievement goal 
than non-stereotype-aware participants in diagnostic conditions, and (c) more highly domain-identified participants will report higher levels of anxiety, lower levels of selfefficacy, and be more likely to report a performance-avoidance achievement goal than less domain-identified participants only when they are stereotype-aware.

\section{Participants}

The participants were the African American third, fourth and fifth grade students at an urban elementary school in a major metropolitan area in South Florida. The student composition of the school was $80 \%$ African American, 19\% Hispanic, and 1\% White, and over $90 \%$ of the students qualified for free or reduced lunch (MDCPS, 2006). The school had never made Adequate Yearly Progress (U.S. Department of Education, 2007) by NCLB standards (based on standardized test scores), and had implemented several test-preparation protocols mandated by the state as a result. These characteristics are typical of many schools in urban centers in the United States (Kozol, 2005). Third, fourth, and fifth graders were chosen because of the particularly high-stakes of their state standardized test. Low performance on this test could result in mandatory retention. Consent forms were signed by the parents or guardians of all participants. A total of 251 students returned signed consent forms, 204 of whom were African American. Although only the data collected from African American students were analyzed, measures were administered to all students who returned signed consent forms in order to maintain a typical environment for participants. A complete set of data on all dependent variables was collected from 198 of the 204 eligible African American students. Six students had withdrawn from the school before the complete battery of assessments was administered. 


\section{Measures}

Stereotype awareness. Following the open-ended approach (Biek, 2006; McKown \& Weinstein, 2003), a written measure was developed that asks participants how a planet where green people did not think blue people were smart was like the real world. Children were scored as being stereotype-aware if their answer referenced racial prejudice, racial discrimination, or racial conflict (see Appendix A).

Domain-identification. Negative stereotypes are more threatening when the performance domain is self-relevant for the individual (Aronson et al., 1999; Cadinu et al., 2003; Keller, 2007; Leyens et al., 2000; Spencer et al., 1999; Stone et al., 1999). Therefore, to expand upon the previous research, the English subsection of the DIM (Smith \& White, 2001), was administered to the participants (the word "Reading" was substituted for "English" on the scale to correspond with course nomenclature). Domain identification was measured with 7 Likert-like survey items related to how good the participants are at reading, as well as to the importance the participants place on reading. These are two crucial aspects of domain-identification as proposed in the conceptualization introduced by Steele (1997). A previous examination of internal consistency measures of the English subsection of the DIM revealed alpha coefficients ranging from .34 to .74 (Smith \& White). To the author's knowledge the measure has never been utilized on a child sample. The measure was thus piloted with a group of 23 third grade students to increase likelihood of comprehension (see Appendix B).

Reading test performance. The primary dependent variable was performance on a reading comprehension activity. The reading comprehension activity consisted of two reading passages from a state-provided sample standardized reading test. The first 
passage was followed by 13 multiple choice questions, and the second was followed by 8 multiple choice questions (for a total of 21 items). Performance was measured by number of questions answered correctly in $30 \mathrm{~min}$. A 2006 analysis of the internal consistency of the FCAT test revealed a Cronbach's alpha coefficient of .89 (Florida Department of Education, 2006b).

Orientation towards a performance-avoidance achievement goal. Goal orientation of participants was measured using the performance-avoid goal orientation (revised) component of the Patterns of Adaptive Learning Scales (PALS) which has been validated for use at the elementary school level (Midgley et al., 2000). The particular component included 4 Likert-scale items, and is publicly available (see Appendix C). A previous examination of internal consistency revealed an alpha coefficient of .74 (Midgley et al.). The measure was also piloted with a group of 23 third grade students to increase the likelihood of comprehension.

Pre-test anxiety. Self-reported anxiety was measured for all participants using the State Anxiety Scale from State Trait Anxiety Inventory for Children (STAIC) (Spielberger et al., 1973). The STAIC has been widely used to assess anxiety in children. Normative data is available for fourth, fifth, and sixth grade students (Spielberger et al.). Much research supports the reliability and validity of this measure. Overall and itemspecific scores increase when compared to baseline reports when children are asked to complete the survey just before a final exam (Spielberger et al., 1973), or in other anxiety provoking conditions (Roberts, Vargo, \& Ferguson, 1989). Previous examinations of internal consistency measures of the STAIC-State subscale revealed alpha coefficients ranging from .71 to .82 (Papay \& Hedl, 1978; Papay \& Spielberger, 1986), and included 
younger students in the analyses. The measure is easy to read and can be administered verbally to younger children, or those with below-average reading abilities. Individuals respond to each item on a 3-point rating scale, checking one of three alternatives that describes him or her best or indicates frequency of occurrence. Additionally, the measure was piloted with a group of 23 third grade students at the research-site to increase the likelihood of comprehension.

Self-efficacy. Self-efficacy was measured for all participants using the academic self-efficacy component of the PALS (Midgley et al., 1996), the validation of which was supported for use at the elementary school level as measurement of students' perceptions of their competence to do their class work (Middleton \& Midgley, 1997). A previous examination of internal consistency revealed an alpha coefficient of .74 (Midgley et al., 2000). The particular component includes 5 Likert-scale items and is publicly available (see Appendix D). The measure was also piloted with a group of 23 third grade students to ensure comprehension.

Procedure

The stereotype-awareness measure was administered to all participants, resulting in a stereotype-aware (SA) and a not stereotype-aware (NA) group. The following procedure was then followed separately for SA and NA participants for purposes of comparison: The English subsection of the DIM was administered, and a median split was performed on the resulting scores to create more domain-identified and less domainidentified groups. Following the administration of the DIM, Steele and Aronson's (1995) methods were applied, manipulating stereotype threat conditions by characterizing a reading test as either a practice standardized test diagnostic of ability, or as a 
nondiagnostic performance task. The more domain-identified and less domain-identified participants were each randomly assigned to either a diagnostic or nondiagnostic testing condition (see Figure 3). The reading comprehension activity was administered in a small classroom setting in pullout groups of between 4 and 8 students. The experimenter prepared students for the activity using a script derived from McKown and Weinstein (2003) by saying, "Now we are going to complete some reading questions. Some are easy and some are hard. You probably will not get all of the questions correct. Let me tell you why we are doing these questions." Then, children in the diagnostic conditions were told:
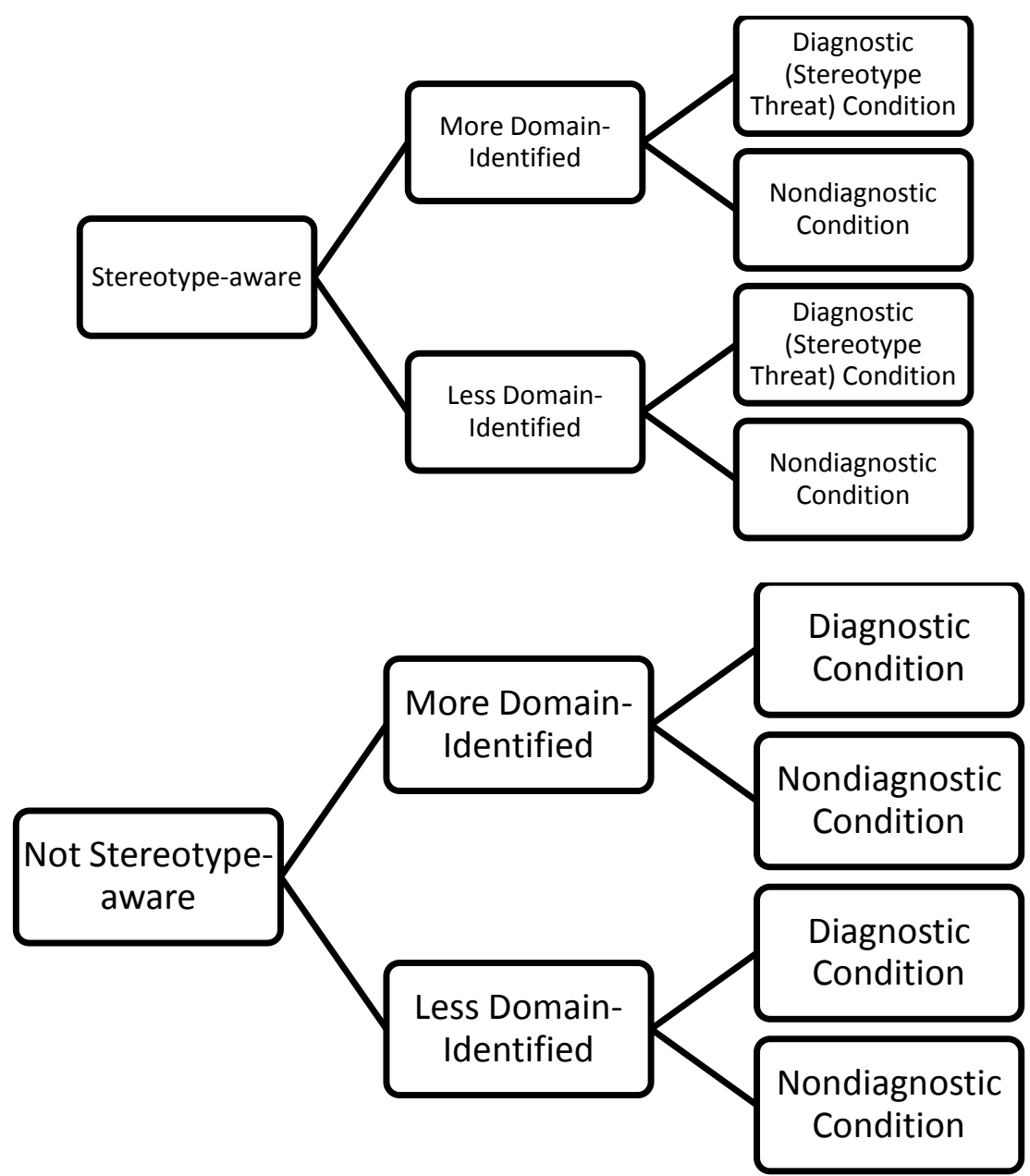

Figure 3. Conditions for quantitative methods. 
"The questions you are going to answer are practice for the FCAT [Florida Comprehensive Achievement Test]. They are a very, very good way of finding out how well you will perform on the actual FCAT. The test is difficult so that I can really find out how well you will do on the FCAT. Please do your best so I can see what you are good at, and what you are not so good at." Students were also asked to bubble in their race. These directions are similar to those the students often hear in their standardized test practice curriculum protocols.

In the nondiagnostic testing conditions, the children were told: "You are about to complete a problem solving activity. This is not a test. The questions are difficult so that I can really see how children solve problems. Please try the best that you can." To increase the likelihood that participants understood the instructions, they were asked to repeat why they were doing the activity and misconceptions were corrected as necessary.

Mediators. After reading comprehension activity directions were given, but before the participants began working, the goal orientation, state anxiety, and selfefficacy of participants was assessed using the appropriate measures.

\section{Pilot Study}

A pilot study was conducted to provide preliminary quantitative data on the effects of stereotype threat on African American elementary students in an urban elementary school. The procedure was identical to that delineated in the Phase 1 methods, with two exceptions: (a) only stereotype-aware students were included, and (b) the final sample included only 17 students from one third grade classroom. 
A 2 (domain-identification) $\mathrm{x} 2$ (threat condition) MANOVA was conducted evaluate the effects of stereotype threat on reading test scores, anxiety, self-efficacy, and goal orientation. There was a significant main effect of threat condition on reading score $F(1,13)=15.81, p<.01$, and a near significant main effect of threat condition on anxiety $F(1,13)=4.32, p=.06$. As hypothesized, participants in the nondiagnostic condition scored significantly higher $(\bar{x}=47.56 \%)$ than participants in the diagnostic condition $(\bar{x}$ $=15.75 \%)$. Also, participants in the nondiagnostic condition reported less anxiety $(\bar{x}=$ 28.65) than participants in the diagnostic condition $(\bar{x}=36.68)$. There were no other significant main effects. This may be due to the small sample size utilized in the pilot study.

There was also a near significant interaction between domain-identification and threat condition on reading score $F(1,13)=2.58, p=.13$. The simple main effects were further analyzed, revealing highly significant differences in reading test scores between threat conditions only for domain-identified participants $F(1,13)=19.15, p<.01$. Domain-identified participants in the nondiagnostic condition scored significantly higher $(\bar{x}=57.80 \%)$ than domain-identified participants in the diagnostic condition $(\bar{x}=$ 15.20\%). Scores differed in the same direction for non-domain-identified participants, however this difference was not statistically significant (see Figure 4). These results were in line with the primary research hypothesis. There were no other significant interactions. This is likely a factor of the small sample size utilized in the pilot study. The results of the pilot study provide preliminary data highlighting the importance of the quantitative phase of the proposed study. 
Phase 2

This segment of the study investigated how African American elementary school students navigated through the school year approaching the state standardized test. Of specific interest was how students perceive factors influencing stereotype threat. The research subquestion guiding phase 2 was: How do African American children perceive and experience the factors related to stereotype threat and navigate through the school year approaching the standardized test?

Qualitative research is an enquiry approach that is grounded in constructivism, the worldview that individuals construct social reality through interpretation of meanings, and that these constructions tend to be transitory and situational (Gall, Gall, \& Borg, 2007). It allows the researcher to examine the contextual complexities and abstract interrelations that can only be researched from the ground up. The advantage of the qualitative phase of my study, and of qualitative research in general, is the depth to which investigations can be conducted. Qualitative researchers focus on phenomena that occurs in natural settings study those phenomena in all their complexity, in an in depth study (Leedy \& Ormrod, 2005).

Bogdan and Biklen (2003) delineate five important features present in qualitative research: (a) qualitative research is naturalistic, (b) it involves descriptive data, (c) qualitative research is concerned with process, (d) it is inductive, and (e) "meaning" is of essential concern. Qualitative research is naturalistic in the sense that the researcher enters the world of the participants to obtain data directly from the source. Observation in the "natural" setting is an advantage because it allows for a deeper understanding of actions, as they are researched in context, and because information can be recorded as it 
occurs (Creswell, 1994). The researcher is the primary instrument of data collection, and the data are descriptive. In the present study, data included interview transcripts and fieldnotes based ob classroom observations. McMillan and Schumacher (2001) describe qualitative research as focusing on what the phenomenon means to participants. In the present study, this allowed for scrutiny of the entire context, and a rich presentation that was absent with just the quantitative phase.

The goal of qualitative research is to understand phenomena from participant perspective. Merriam (2002) states that the researcher can approach the phenomenon from three different stances: interpretive, critical, or postmodern. Researchers adopting an interpretive qualitative stance are interested in understanding how individuals experience their social reality. Critical and postmodern studies have goals that include, but go beyond understanding. Researchers who draw from the critical stance also investigate how larger sociopolitical contextual factors affect the ways in which this social reality is constructed. As put by Merriam, "How do power, privilege, and oppression play out?" (p. 4). Researchers that draw from the postmodern stance challenge the very form and construction of qualitative research.

A critical stance was maintained in the qualitative phase of this study, specifically critical race theory in education (CRT). CRT provides an alternative theoretical framework through which to conduct qualitative research in education by differentiating between the dominant discourse and the experiential knowledge of people of color (Duncan, 2002b). The research has demonstrated that by utilizing a counter-storytelling method, researchers can incorporate the perspectives of people of color (DeCuir \& Dixson, 2004; Solorzano \& Yosso, 2002). In order to characterize stereotype threat 
effects of children through a CRT lens, it was important to understand completely their subjective experience in this context. In an attempt to address this phenomenon, this segment of the current study sought to acquire, through in-depth focus group interviews and classroom observations, a comprehensive record of factors that produced or perpetuated stereotype threat effects for a group of African American children. Their accounts were used to develop a counter-story.

\section{Participants}

The participants were a purposefully selected group of 4 of the SA African American elementary school students found to be highly domain-identified with reading in Phase 1 of the study. Since more highly domain-identified students significantly outperformed less domain-identified students in Phase 1, the participants were some of the top performing students in their Reading class. Purposeful sampling is defined as "the process of selecting cases that are likely to be 'information rich' with respect to the purposes of a qualitative research study" (Gall et al., 2007, p. 650). For this reason, the students' teachers assisted the researcher in selecting a sample of students likely to be communicative and articulate. The final sample included 4 nine year-olds; 2 boys ("Floyd" and "Johnny") and 2 girls ("Asia" and "LaTavia"). Signed parental consent forms were received from the participants.

\section{Role of the Researcher}

The researcher, a White male, was formerly a teacher at the research site. Although none of the participants were ever in his class, he had an established rapport with several staff members, students, and parents. This facilitated access to the school in 
that he was not viewed as an "other," but instead as a former teacher coming back to visit.

\section{Procedure}

The design of the study included focus group interviews supplemented by classroom observations. Focus group interviews were utilized to illustrate in greater detail the participants' standardized testing experiences. According to Solorzano et al. (2000) focus groups have four specific strengths, to: "(a) explore and discover concepts and themes about a phenomena about which more knowledge is needed, (b) add context and depth to the understanding of the phenomena, (c) provide an interpretation of the phenomena from the point of view of the participants in the group, and (d) observe the collective interaction of the participants" (p. 64). The researcher interviewed participants on six occasions throughout the school year with questions related to identity salience, stereotype awareness, goal orientation, test anxiety, and domain-identification related to the FCAT. Each focus group lasted approximately $45 \mathrm{~min}$. The focus group interviews were semistructured. Semistructured interviews allow the interviewer and the interviewees the flexibility to probe for details or discuss issues (Gall et al., 2007). A framework for each focus group interview was developed beforehand (see Appendix E). As the interviews continued, I adapted the initial framework to create an outline of interview questions more specific to the participants, and to provide time for elaboration on past comments. The focus groups were taped and transcribed verbatim. After each focus group interview was transcribed, participants were permitted to listen the tape and suggest any changes to their comments that they deemed necessary. 
Following participant review of the interviews, a data analysis plan rooted in grounded theory was implemented. Grounded theory (Glaser \& Strauss, 1967; Strauss \& Corbin, 1998) is a research method that seeks to develop theory that is grounded in data systematically gathered and analyzed. According to Denzin and Lincoln (2000) grounded theory methods consist of "systematic inductive guidelines for collecting and analyzing data to build middle-range theoretical frameworks that explain the collected data" ( $\mathrm{p}$. 509). In other words, the theory is "grounded" in the specific data that have been collected by the researcher. A grounded theory orientation allows categories to emerge from the data, which are gathered primarily through interviews and meticulous observation.

Data analysis for researchers who are utilizing a grounded theory approach involves three processes (Strauss \& Corbin, 1998): (a) open coding, where data are thoroughly raked through in an effort to identify relevant categories, (b) axial coding, where, from these categories, common themes emerge, which are the basis for the theory development, and (c) selective coding, which ties all themes together to form a core category and overarching theory. In this vein, the researcher first categorized similar statements of experience. This was accomplished through a detailed line-by-line analysis. In order to systematically analyze the data, codes were applied. Once each transcript was coded, the coded passages were reanalyzed to develop cogent categories related to standardized testing experiences and processes mediating stereotype threat. The passages were then grouped and reorganized into themes. Conclusions on perceptions of influencing factors were drawn from these themes and subthemes that emerged from the data. 
The data were supplemented with fieldnotes from classroom observations. The classroom observations took place in 1-hour blocks over a 4 month period, for a total of $30 \mathrm{hrs}$. Throughout the research, during most visits to the school site, the researcher spent one hour as an observer in the reading classroom of the qualitative phase participants. The researcher observed and recorded notes on daily classroom activities including but not limited to test practice protocols, student-teacher interactions, student-student interactions, and classroom visits from administrative personnel. During later classroom observations, special attention was paid to situations related to comments made by students on during focus-group interviews. The observations complemented the researchers own experiences as a classroom teacher of third and fourth grade students at the research site for 8 years. The classroom observations and member checking served as forms of triangulation. The data were utilized to develop a counter-story (DeCuir \& Dixson, 2004; Solorzano \& Yosso, 2002) to a dominant discourse that stigmatizes African American students.

The qualitative component in this study was necessary to sharpen and broaden our knowledge of the stereotype threat phenomenon. Qualitative study of the stereotype threat phenomenon had largely been neglected. The quantitative measures of test scores and the potential mediating factors of stereotype threat (e.g., self-efficacy) fail to capture some of the issues that are exemplified by qualitative investigation (e.g., Milner \& Hoy, 2003). In addition, qualitative investigation was needed to refine our understanding by capturing firsthand accounts of the contextual factors surrounding this phenomenon. Coupled with the quantitative phase, the qualitative phase provided a deeper understanding of actions, as they were researched in context, and the data were gathered 
from the perspective of the participants. This allowed for a thorough examination of the entire context, whereas rich data would have been absent with only the quantitative phase. Examined together, the quantitative and qualitative phases provided a more comprehensive and complementary analysis of the stereotype threat phenomenon, and how it affects African American elementary school students in an urban elementary school preparing for a high-stakes standardized test. 


\section{CHAPTER IV}

\section{FINDINGS}

This chapter presents the findings and is divided into two sections: Phase 1 and Phase 2. Phase 1 presents the quantitative findings, addressing research subquestions 1 4. Phase 2 presents the qualitative findings, addressing research subquestion 5 , and relating qualitative findings to quantitative findings.

\section{Phase 1 Results}

In the quantitative phase of the study, two $2 \times 2$ experimental designs were utilized; one for SA participants, and one for NA participants. The factors for each group of participants were: (a) level of participant domain-identification with regard to reading, and (b) a test description factor, where the reading activity was presented as either a diagnostic practice standardized test or a nondiagnostic problem-solving activity. This section reports on the results of the quantitative data analysis in the order of the research subquestions presented above. Data were collected on 198 of the 204 eligible African American students $(N=198)$. See Table 2 for the number of participants in each condition by grade level. The 198 participants were first divided into 2 groups, SA ( $n=$ $95)$ and NA $(n=103)$. Then, a median split was performed on each of these groups based on participants' scores on the English subsection of the DIM, yielding more highly domain-identified and less domain-identified subgroups for both SA $(\mathrm{Mdn}=28)$ and NA $(\mathrm{Mdn}=28)$ participants (see Table 3 for descriptive statistics of the scores on the English subsection of the DIM). Data on reading performance were collected for all participants, as were the potential mediating factors of performance goal orientation, pre-test anxiety, and self-efficacy (see Tables 4 through 6 for descriptive statistics on the data for each 
measure for each condition). Detailed analysis of the data in the order of the research questions follows.

Table 2

Number of Participants in Each Condition by Grade Level.

Stereotype- Not stereotypeaware aware

\begin{tabular}{|c|c|c|c|c|}
\hline \multirow[t]{9}{*}{$\begin{array}{l}\text { More Domain- } \\
\text { Identified }\end{array}$} & Diagnostic & Third Grade & 10 & 9 \\
\hline & & Fourth Grade & 11 & 11 \\
\hline & & Fifth Grade & 6 & 7 \\
\hline & & All Grades & 27 & 27 \\
\hline & Nondiagnostic & Third Grade & 9 & 13 \\
\hline & & Fourth Grade & 9 & 8 \\
\hline & & Fifth Grade & 6 & 7 \\
\hline & & All Grades & 24 & 28 \\
\hline & Both & & 51 & 55 \\
\hline \multirow[t]{9}{*}{$\begin{array}{l}\text { Less Domain- } \\
\text { Identified }\end{array}$} & Diagnostic & Third Grade & 5 & 12 \\
\hline & & Fourth Grade & 10 & 6 \\
\hline & & Fifth Grade & 8 & 6 \\
\hline & & All Grades & 23 & 24 \\
\hline & Nondiagnostic & Third Grade & 4 & 7 \\
\hline & & Fourth Grade & 10 & 11 \\
\hline & & Fifth Grade & 7 & 6 \\
\hline & & All Grades & 21 & 24 \\
\hline & Both & & 44 & 48 \\
\hline
\end{tabular}


Table 3

Participant Scores on the English Subsection of the Domain Identification Measure by Stereotype Awareness.

\begin{tabular}{llccc}
\hline \multirow{2}{*}{ Total } & & $\mathrm{N}$ & Range & Mean (SD) \\
\cline { 3 - 5 } & & 198 & $14-35$ & $27.44(4.36)$ \\
\hline Stereotype-aware & Less Domain-Identified & 44 & $15-27$ & $23.61(2.78)$ \\
& More Domain-Identified & 51 & $28-35$ & $31.02(2.16)$ \\
& Both & 95 & $15-35$ & $27.59(4.45)$ \\
& & & & \\
\hline Not stereotype-aware & Less Domain-Identified & 48 & $14-27$ & $23.75(3.23)$ \\
& More Domain-Identified & 55 & $28-35$ & $30.42(2.15)$ \\
& Both & 103 & $14-35$ & $27.31(4.29)$
\end{tabular}

Stereotype Threat and Reading Test Performance (Subquestion 1)

Research subquestion 1 asked if the reading test performance of African American elementary school students is related to their awareness of racial stereotypes. Specifically it asked if a diagnostic situation has an influence on the reading test performance of African American elementary school students aware of racial stereotypes. It was hypothesized that African American elementary school students who are aware of the societal stereotype of African American intellectual inferiority will significantly underperform on a reading comprehension activity framed as a test diagnostic of intelligence, as compared to when the same activity is framed as nondiagnostic of intelligence. 
Table 4

Descriptive Statistics on Dependent Variable Measures for Stereotype Aware Participants.

\begin{tabular}{|c|c|c|c|c|c|c|c|c|c|c|}
\hline & & & $\begin{array}{r}\text { Per } \\
\text { avoidanc } \\
\text { goal } \\
\end{array}$ & $\begin{array}{l}\text { rmance- } \\
\text { achievement } \\
\text { rientation }\end{array}$ & & efficacy & Pre & st anxiety & & $\begin{array}{l}\text { ling test } \\
\text { ormance }\end{array}$ \\
\hline & & $\underline{\mathrm{N}}$ & Range & $\mathrm{M}(\mathrm{SD})$ & Range & $\mathrm{M}(\mathrm{SD})$ & Range & $\mathrm{M}(\mathrm{SD})$ & Range & $\mathrm{M}(\mathrm{SD})$ \\
\hline \multirow[t]{3}{*}{ MDI } & D & 27 & $8-20$ & $13.74(3.23)$ & $16-25$ & $21.48(2.41)$ & $20-44$ & $32.31(6.26)$ & $0-90$ & $45.30(23.22)$ \\
\hline & ND & 24 & $8-18$ & $14.17(2.70)$ & $16-25$ & $20.92(2.65)$ & $20-37$ & $27.96(4.96)$ & $33-100$ & 71.04 (17.96) \\
\hline & Both & 51 & $8-20$ & $13.94(2.97)$ & $16-25$ & $21.22(2.52)$ & $20-44$ & $30.29(6.05)$ & $0-100$ & $57.41(24.44)$ \\
\hline \multirow[t]{3}{*}{ LDI } & D & 23 & $6-20$ & $14.04(3.74)$ & $12-25$ & $19.70(3.57)$ & $23-53$ & $34.52(6.87)$ & $0-76$ & $36.13(20.04)$ \\
\hline & ND & 21 & $6-20$ & $13.38(3.34)$ & $11-25$ & $17.67(3.77)$ & $21-45$ & $33.00(7.57)$ & $13-86$ & $48.24(22.01)$ \\
\hline & Both & 44 & $6-20$ & $13.73(3.53)$ & $11-25$ & $18.73(3.77)$ & $21-53$ & $33.80(7.17)$ & $0-86$ & 41.91 (21.64) \\
\hline \multirow[t]{3}{*}{ Total } & D & 50 & $6-20$ & $13.88(3.44)$ & $12-25$ & $20.66(3.10)$ & $20-53$ & $33.36(6.57)$ & $0-90$ & 41.08 (22.09) \\
\hline & ND & 45 & $6-20$ & $13.80(3.00)$ & $11-25$ & $19.40(3.58)$ & $20-45$ & $30.31(6.73)$ & $13-100$ & $60.40(22.83)$ \\
\hline & Both & 95 & $6-20$ & $13.84(3.22)$ & $11-25$ & $20.06(3.38)$ & $20-53$ & $31.92(6.79)$ & $0-100$ & $50.23(24.33)$ \\
\hline
\end{tabular}

Note. Performance-avoidance achievement goal orientation as measured by the performance-avoid goal orientation (revised) component of the PALS. Self-efficacy as measured by the academic self-efficacy component of the PALS. Pre-test anxiety as measured by the state anxiety subsection of the STAIC. Reading test performance as measured by percent correct on a practice FCAT. MDI = more highly domain-identified with reading; LDI = less domain-identified with reading; $\mathrm{D}=$ diagnostic condition; $\mathrm{ND}=$ nondiagnostc condition. 
Table 5

Descriptive Statistics on Dependent Variable Measures for Not Stereotype Aware Participants.

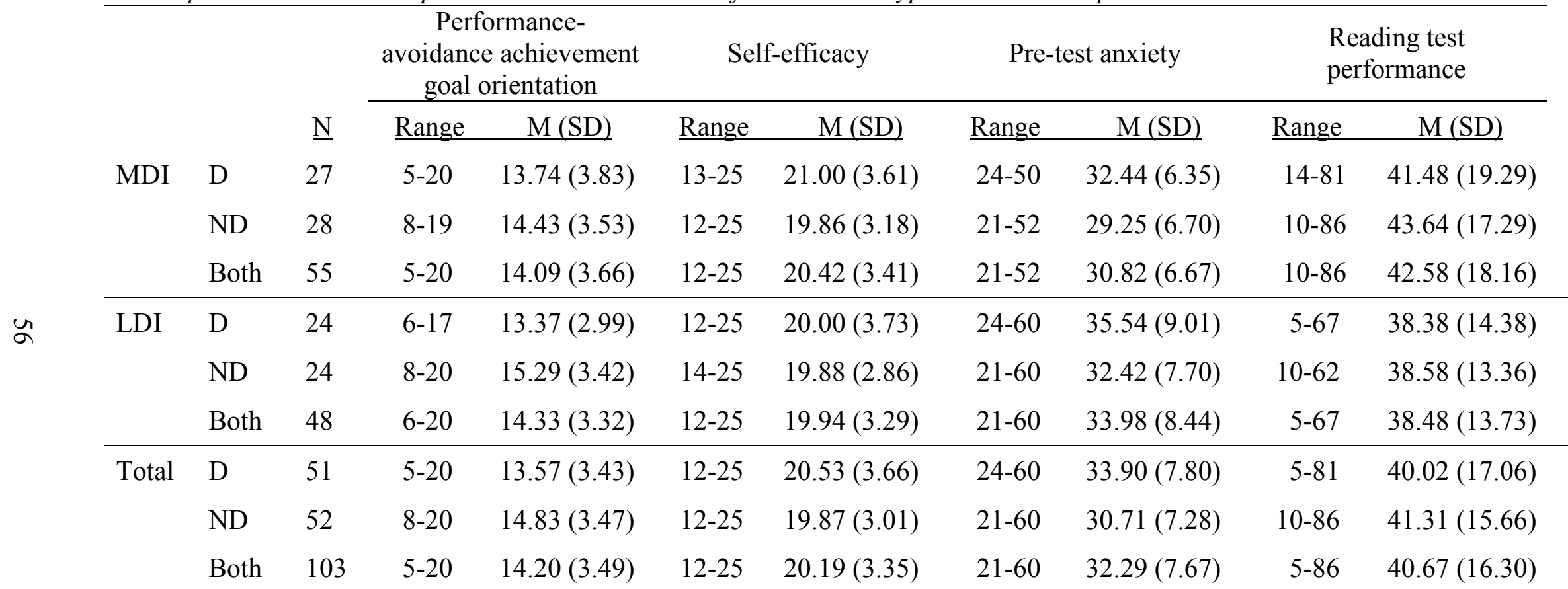

Note. Performance-avoidance achievement goal orientation as measured by the performance-avoid goal orientation (revised) component of the PALS. Self-efficacy as measured by the academic self-efficacy component of the PALS. Pre-test anxiety as measured by the state anxiety subsection of the STAIC. Reading test performance as measured by percent correct on a practice FCAT. MDI = more highly domain-identified with reading; LDI = less domain-identified with reading; $\mathrm{D}=$ diagnostic condition; $\mathrm{ND}=$ nondiagnostc condition. 
Table 6

Descriptive Statistics on Dependent Variable Measures for All Participants.

\begin{tabular}{|c|c|c|c|c|c|c|c|c|c|c|}
\hline \multirow[b]{3}{*}{ MDI } & \multirow[b]{3}{*}{$\mathrm{D}$} & \multirow[b]{2}{*}{$\underline{\mathrm{N}}$} & \multicolumn{2}{|c|}{$\begin{array}{c}\text { Performance- } \\
\text { avoidance achievement } \\
\text { goal orientation }\end{array}$} & \multicolumn{2}{|c|}{ Self-efficacy } & \multicolumn{2}{|c|}{ Pre-test anxiety } & \multicolumn{2}{|c|}{$\begin{array}{l}\text { Reading test } \\
\text { performance }\end{array}$} \\
\hline & & & $\underline{\text { Range }}$ & $\mathrm{M}(\mathrm{SD})$ & Range & $\mathrm{M}(\mathrm{SD})$ & $\underline{\text { Range }}$ & $\mathrm{M}(\mathrm{SD})$ & $\underline{\text { Range }}$ & $\mathrm{M}(\mathrm{SD})$ \\
\hline & & 54 & $5-20$ & $13.74(3.51)$ & $13-25$ & $21.24(3.05)$ & $20-50$ & $32.41(6.25)$ & $0-90$ & $43.39(21.23)$ \\
\hline & $\mathrm{N}$ & 52 & $8-19$ & $14.31(3.15)$ & $12-25$ & $20.35(2.97)$ & $20-52$ & $28.65(5.94)$ & $10-100$ & $56.29(22.22)$ \\
\hline & Both & 106 & $5-20$ & $14.02(3.33)$ & $12-25$ & $20.80(3.03)$ & $20-52$ & $30.57(6.35)$ & $0-100$ & $49.72(22.57)$ \\
\hline \multirow[t]{3}{*}{ LDI } & $\mathrm{D}$ & 47 & $6-20$ & $13.70(3.36)$ & $12-25$ & $19.85(3.62)$ & $23-60$ & $35.04(7.96)$ & $0-76$ & $37.28(17.23)$ \\
\hline & ND & 45 & $6-20$ & $14.40(3.48)$ & $11-25$ & $18.84(3.46)$ & $21-60$ & $32.69(7.56)$ & $10-86$ & $43.09(18.36)$ \\
\hline & Both & 92 & $6-20$ & $14.04(3.42)$ & $11-25$ & $19.36(3.56)$ & $21-60$ & $33.89(7.82)$ & $0-86$ & $40.12(17.93)$ \\
\hline \multirow[t]{3}{*}{ Total } & $\mathrm{D}$ & 101 & $5-20$ & $13.72(3.42)$ & $12-25$ & $20.59(3.38)$ & $20-60$ & $33.63(7.18)$ & $0-90$ & $40.54(19.62)$ \\
\hline & ND & 97 & $6-20$ & $14.35(3.29)$ & $11-25$ & $19.65(3.28)$ & $20-60$ & $30.53(7.00)$ & $10-100$ & $50.16(21.46)$ \\
\hline & Both & 198 & $5-20$ & $14.03(3.36)$ & $11-25$ & $20.13(3.36)$ & $20-60$ & $32.11(7.25)$ & $0-100$ & $45.26(21.05)$ \\
\hline
\end{tabular}

Note. Performance-avoidance achievement goal orientation as measured by the performance-avoid goal orientation (revised) component of the PALS. Self-efficacy as measured by the academic self-efficacy component of the PALS. Pre-test anxiety as measured by the state anxiety subsection of the STAIC. Reading test performance as measured by percent correct on a practice FCAT. MDI = more highly domain-identified with reading; LDI = less domain-identified with reading; $\mathrm{D}=$ diagnostic condition; $\mathrm{ND}=$ nondiagnostc condition. 
A 2 (stereotype-awareness) x 2 (diagnosticity) ANOVA was conducted to evaluate the effect of stereotype threat on the reading test performance of African American elementary school students. The results supported the hypothesis, such that a significant interaction emerged between stereotype-awareness and whether or not the test was presented as diagnostic of intelligence $(F[1,194]=10.53, p<.05)$. Because the interaction was significant, main effects were ignored and simple main effects were examined. That is, the differences among students who were not aware of racial stereotypes (NA) and the difference among those who were aware of racial stereotypes (SA) were analyzed separately. To control for Type I error across the two simple main effects, alpha for each was set at .025 . There were no significant differences in reading test performance between conditions for NA students $(F[1,194]=.11, p=.74)$. However, there were significant differences in reading test performance between diagnostic and nondiagnostic conditions for SA students $(F[1,194]=2.21, p<.01)$. As hypothesized, SA participants in the nondiagnostic condition scored significantly higher $(M=60.40 \%)$ than SA participants in the diagnostic condition $(M=41.08 \%)$. These results suggest that the significant simple main effects for SA students are related to stereotype threat (See Figure 4).

Domain-Identification (Subquestion 2a)

Research subquestion $2 \mathrm{a}$ asked if level of domain-identification with reading is related to the test performance of African American elementary school students. It was hypothesized that more highly domain-identified African American students $(n=106)$ would score higher on a reading test than their less domain-identified $(n=92)$ counterparts. A one-way analysis of variance was conducted to evaluate the relationship 


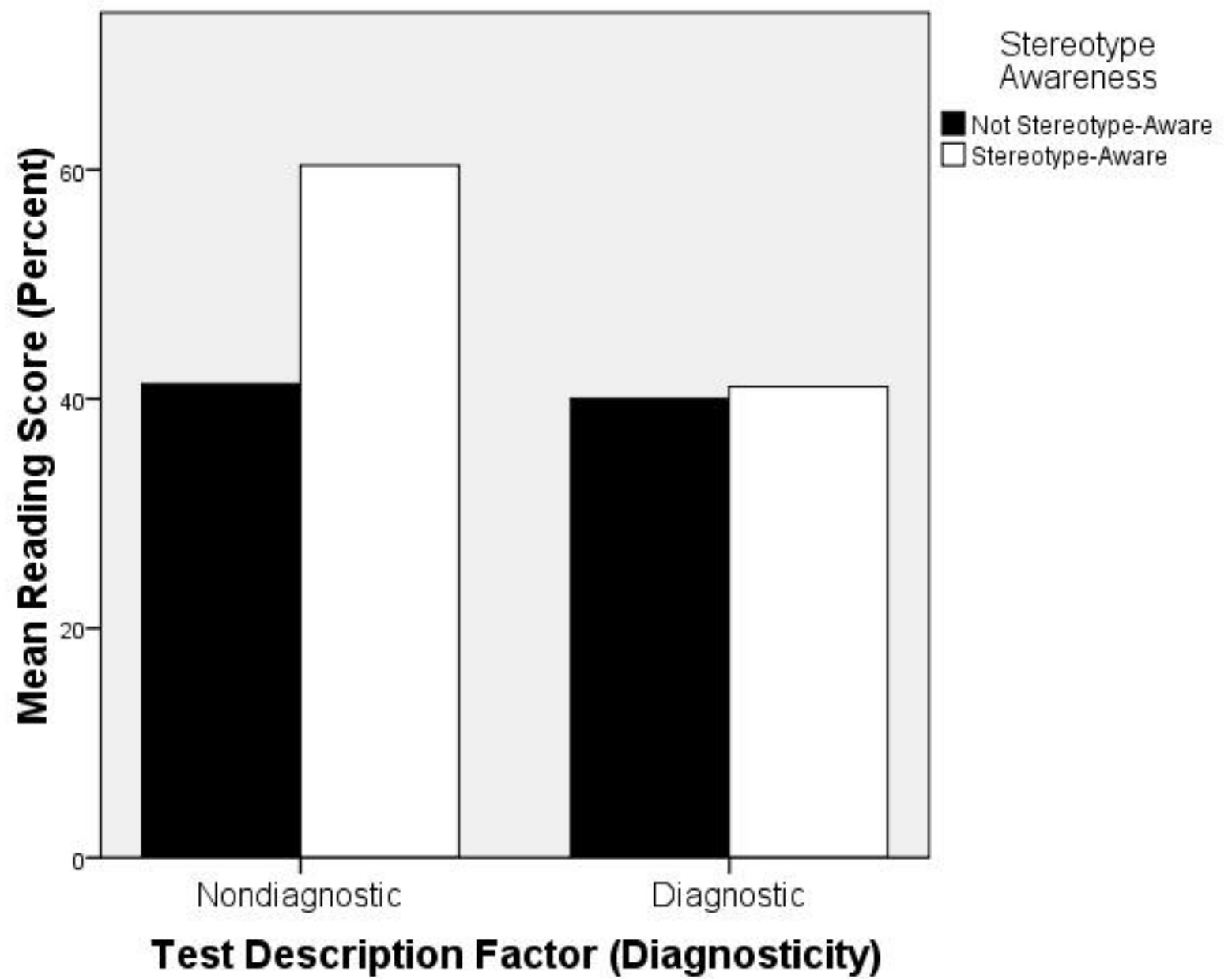

Figure 4. Effect of threat condition on the reading test performance of African American elementary school students.

between level of domain-identification and reading test performance. Results supported the hypothesis, such that more highly domain-identified students performed significantly better $(\mathrm{M}=49.72 \%)$ than less domain-identified students $(\mathrm{M}=40.12 \% ; F[1,196]=$ $10.75, p<.05)$. 
Domain-Identification related to Stereotype Threat and Reading Test Performance

(Subquestion 2b)

Research subquestion $2 \mathrm{~b}$ asked if level of domain-identification with reading is related to the influence of a diagnostic testing situation on the reading test performance of African American elementary school students aware of racial stereotypes. To evaluate the relationship between domain-identification and the influence of stereotype threat on the reading test performance of African American elementary school students, only SA students $(n=95)$ were used in data analysis (Again, there were no significant differences in reading test scores between conditions for NA students). A 2 (domain-identification) $\mathrm{x}$ 2 (threat condition) ANOVA was conducted to evaluate the effects of stereotype threat and domain identification on reading test performance of SA African American students. There was a significant main effect of level of domain-identification on reading score, $F(1,91)=13.71, p<.05$. Specifically, more highly domain-identified participants $(n=$ 51) scored higher than less domain-identified participants $(n=44)$. There was also a significant main effect of threat condition on reading score, $F(1,91)=19.22, p<.05$. In other words, participants in the nondiagnostic condition scored higher than participants in the diagnostic condition.

However, it was specifically hypothesized that SA students who reported a high level of domain-identification with reading will underperform in the diagnostic condition. To test for this hypothesis, the simple main effects were further analyzed. To control for Type I error across the two simple main effects, alpha for each was set at .025 . The data supported the hypothesis. The analysis of simple main effects revealed significant differences in reading test scores between nondiagnostic and diagnostic threat conditions only for the more highly domain-identified SA participants $(F[1,91]=19.18, p<.01)$. 
The highly domain-identified SA participants in the nondiagnostic condition scored significantly better ( $\bar{x}=71.04 \%)$ than the highly domain-identified SA participants in the diagnostic condition $(\bar{x}=45.30 \%)$. Scores differed in the same direction for the less domain-identified participants, however this difference was not statistically significant, $F(1,91)=3.67, p=.06($ see Figure 5$)$.

\section{Stereotype-Aware Participants}

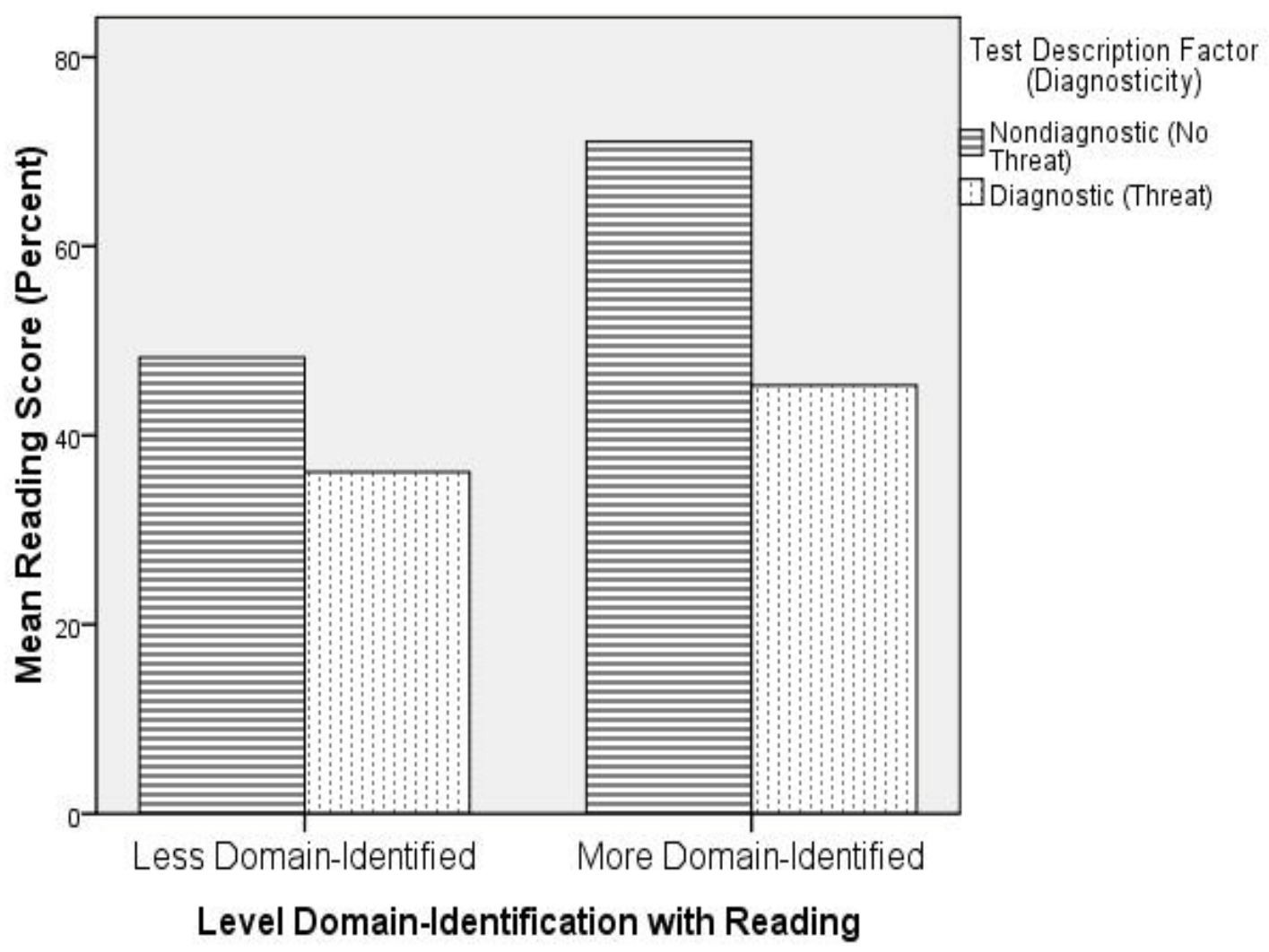

Figure 5. Influence of domain-identification on the stereotype threat reading test performance effects for SA African American elementary school students. 


\section{Stereotype Threat and Mediating Factors (Subquestion 3)}

Research subquestion 3 asked if the pre-test anxiety, self-efficacy, and performance goal orientation of African American elementary school students are related to their awareness of racial stereotypes. More specifically it asked if a diagnostic situation is related to the pre-test anxiety, self-efficacy, and achievement goal orientation of African American elementary school students aware of racial stereotypes. First, it was hypothesized that, overall, participants in diagnostic conditions will report higher levels of pre-test anxiety, and lower levels of self-efficacy than participants in nondiagnostic conditions. Secondly it was hypothesized that, specifically, SA participants in diagnostic conditions will report higher levels of anxiety, lower levels of self-efficacy, and be more likely to report a performance-avoidance achievement goal than NA participants in diagnostic conditions.

One-way MANOVAs were conducted for both SA $(n=95)$ and NA participants $(n=103)$ to evaluate the effect of presenting a test as diagnostic of intelligence on pretest anxiety, self-efficacy, and orientation towards a performance avoidance achievement goal. There was a significant effect of diagnosticity on level of pre-test anxiety for both SA, $F(1,93)=4.98, p<.05$, and NA participants, $F(1,101)=4.61, p<.05$. Overall, students in diagnostic conditions reported significantly more pre-test anxiety $(\mathrm{M}=33.63)$ than did students in nondiagnostic conditions $(\mathrm{M}=30.53)$. The MANOVAs revealed no other significant effects. Additionally, there was no significant interaction between stereotype awareness and diagnosticity in relation to any of the mediating factors (anxiety, $F[1,194]=.01, p=.94$; self-efficacy, $F[1,194]=.39, p=.53$; orientation towards a performance-avoid achievement goal, $F[1,194]=1.97, p=.16)$. 
Domain-Identification related to Stereotype Threat and Mediators (Subquestion 4)

Research subquestion 4 asked if level of domain-identification with reading is specifically related to the influence of a diagnostic testing situation on the anxiety, selfefficacy, and achievement goal orientation of African American elementary school students aware of racial stereotypes? To evaluate the relationship between domainidentification and the influence of diagnosticity on pre-test anxiety, self-efficacy, and orientation towards a performance avoidance achievement goal, 2 (domain-identification) x 2 (diagnosticity) MANOVAs were conducted for both SA $(n=95)$ and NA participants $(n=103)$. Data were analyzed for both groups because significant differences in pre-test anxiety were found for both sets of participants.

For SA participants, there was a significant main effect of level of domainidentification on anxiety $(F[1,91]=7.36, p<.05)$. More highly domain-identified students reported significantly less pre-test anxiety $(M=30.29)$ than did less domainidentified students $(M=33.80)$. There was also a significant main effect for level of domain-identification on self-efficacy $(F[1,91]=15.48, p<.05)$. More highly domainidentified students reported a significantly higher level of self-efficacy $(M=21.22)$ than did less domain-identified students $(\mathrm{M}=18.73)$.

For NA participants, there was a significant main effect of level of domainidentification on only anxiety $(F[1,99]=4.53, p<.05)$. More highly domain-identified students reported significantly less pre-test anxiety $(M=30.82)$ than did less domainidentified students $(\mathrm{M}=33.98)$. 
However, it was specifically hypothesized that SA students who are domainidentified with reading will comparatively experience more pre-test anxiety, lower levels of self-efficacy, and be more likely to report a performance-avoidance achievement goal than those who are less domain-identified, thereby suggesting that the pressure of diagnostic testing has a more significant negative effect on a subset of the stereotyped group that more closely ties their identity to the reading test results. To test this hypothesis, the simple main effects were further analyzed for SA participants. To control for Type I error across the two simple main effects, alpha for each was set at .025. The analysis of simple main effects revealed significant differences in reported pre-test anxiety between nondiagnostic and diagnostic threat conditions only for the more highly domain-identified participants $(F[1,91]=5.97, p<.025)$. The highly domain-identified participants in the nondiagnostic condition reported significantly less anxiety $(M=27.96)$ than the highly domain-identified participants in the diagnostic condition $(\mathrm{M}=32.37)$. Scores differed in the same direction for the less domain-identified participants, however this difference was not statistically significant, $F(1,91)=0.61, p=.44$ (see Figure 6 ). No significant simple main effects were discovered for any of the other dependent variables. The simple main effects were further analyzed for NA participants as well, these analyses revealed no significant differences.

\section{Phase 2 Findings}

Research subquestion 5 asked how African American children perceive and experience the factors related to stereotype threat and navigate through the school year approaching the standardized test. To provide an answer for this subquestion, this section describes the findings from the qualitative data and offers some general comments on 


\section{Stereotype-Aware Participants}

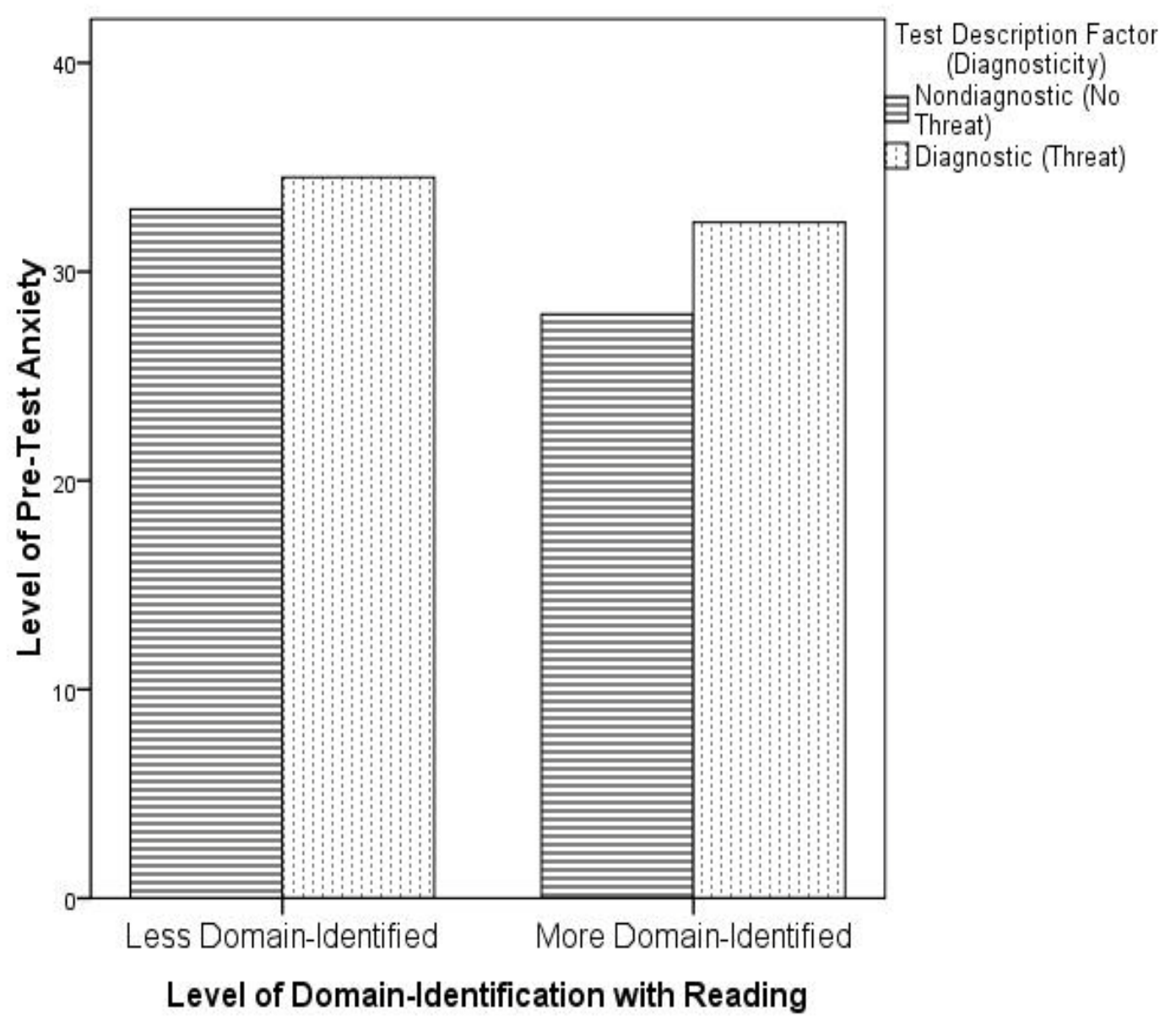

Figure 6. Influence of domain-identification on the stereotype threat pre-test anxiety for SA African American elementary school students.

how test preparation curricular protocols in the urban elementary school context lead to an environment susceptible to stereotype threat experiences for African American students. Using Figure 7 as a guide, this section explores four themes that emerged from the data: (a) a narrow perception of education as strictly test preparation, (b) feelings of stress and anxiety related to the state test, (c) concern with what "others" think (racial salience), and (d) stereotypes. Participants expressed an overall perception of test 


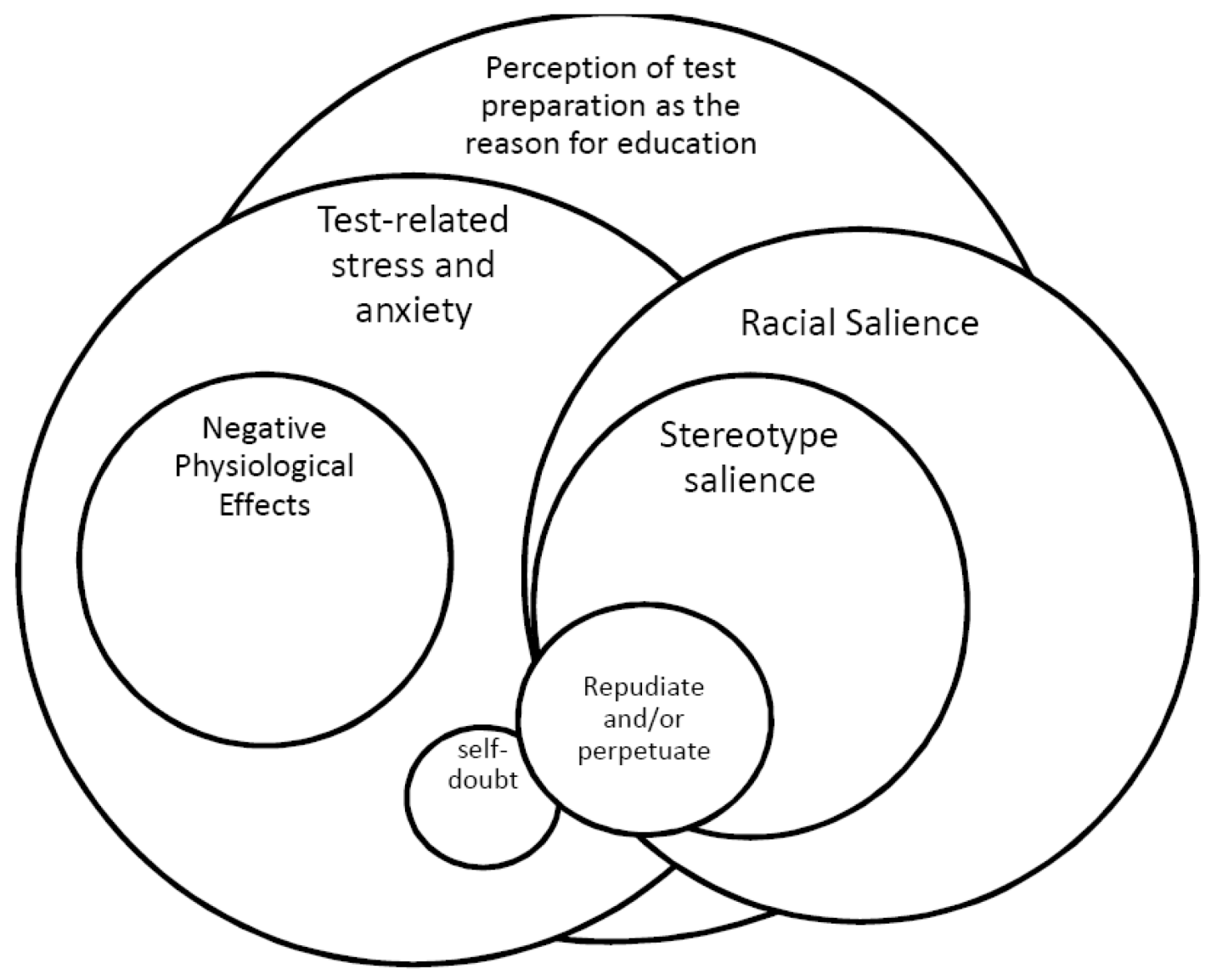

Figure 7. Themes that emerged from qualitative data.

preparation as the reason for education, as represented by the center circle. This

perception was complemented by 2 major overlapping themes related to stereotype

threat: feelings of anxiety, and concern with what "others" think (racial salience).

Students were more likely to report feelings of stress and anxiety when the purpose of education was most narrowly associated with standardized test preparation, and students were likely to reference what "others" thought in terms of stereotypes. This is represented by the intersecting circles: Anxiety was sometimes expressed as related only to test preparation, whereas in other instances it was also related to racial salience. Within the 
theme of racial salience, race-based stereotypes were a salient part of the interviews, and students either repudiated or perpetuated these stereotypes, sometimes associating these stereotypes with their anxiety. In this vein, subthemes were created as the codes were analyzed. Specifically under the stereotypes theme, subthemes included (a) perpetuation and (b) repudiation of relevant stereotypes. Also, under the anxi ety theme, subthemes included (a) physiological consequences, and (b) feelings related to self-doubt.

\section{Education as Test Preparation}

Students... take preliminary tests before they leave the eighth grade, eighty percent fail because of bad preparation, they enter high school labeled failures and their entire ninth grade year becomes test preparation. They have learned that education is a brittle, abstract ritual to ready them for an examination. If they get to college they do not know how to think. They know how to pass the tests and this may get them into college, but it cannot keep them there. We teach them failure. (Kozol, 1992, p. 144)

In the above quote, Kozol describes a bleak future for many African American middle and high school students. Findings from the focus group interviews indicate that African American elementary school students may perceive test preparation as the purpose for education as well. The high-achieving fourth grade focus group participants spoke almost solely of standardized test preparation in descriptions of their day. Asia clearly explained, "We have to do this book, FCAT Advantage, in Math and Reading, and it helps us to understand more about the FCAT...almost every day for the whole year." Field observations made it clear that in a large respect, the classrooms were test preparation centers. During one-third of the field observations, the researcher spent the majority of the time observing students take a practice test. Floyd describes vividly what the reading class is like when it was in test preparation mode, "[The teachers] will never 
let you get up, not even to get your paper or pencil...it takes mostly all of the day." LaTavia agreed, offering the following statement, “Sometimes you can't even get up to use the bathroom." Asia added, "you can't even get water. I was so thirsty...for an hour.” Teachers followed strict protocols dictated by administration. Low-performing schools are mandated to document a certain amount of test-practice throughout the year. In turn, the teachers at the school site, and at other similar school sites nationwide (Meier $\&$ Wood, 2004), were mandated to use test practice books and scripted curricular protocols that they would likely not use otherwise. Field observations made it clear that a large majority of the assignments written on the board were tied to an "FCAT Benchmark" or an "FCAT Strategy" listed with a corresponding page in the test practice booklets. The state test was a salient part of their day-to-day lessons.

The focus group participants professed a belief that without the state test, it is likely that no real education would take place. LaTonya stated, "the school, without FCAT, would be - I don't know how the kids would go on to the next grade if they don't know anything. They'll be kind of slow, and they won't know the stuff." Asia predicted, "school would be just messing around all the time," and Johnny added that there would "be kids bouncing off the walls." The participants believed the test to be necessary, that no education would take place without it. Floyd explained, "We need the FCAT to determine that you are going to the higher grade." Data from the focus group interviews clearly indicated that this group of students viewed the test as the driving force for the curriculum.

Another indication of the salience of the state test occurred when asking the students to describe the work they do in reading class. They answered in terms of state 
benchmarks. Field observations indicated that, as mandated, teachers display the weekly benchmark on the board for each subject in each classroom. For Reading, on one typical day the board read, "LA.A.2.2.2: Identifies the author's purpose in a simple text. FCAT Benchmark: Author's Purpose.”

Asia explained, "the questions are asking about the pictures, and you have to do 'Records and Research,' or it might be asking about 'Plot Development.'” LaTonya chimed in, "and all different benchmarks... 'Cause and Effect', and mostly, 'Author's Purpose." Students are also asked to phrase their oral answers in "FCAT terms." In addition, LaTonya talked about why Reading class was so long, “we don’t do Social Studies anymore because our teachers, they want to do the basic ones that they know that we're gonna get on the FCAT, like Math and Reading." Unfortunately, this unfolded as true. During several field observations, it became clear that Reading class often stretched through the time allotted for Social Studies instruction.

If they were teachers, however, these high-achieving fourth-graders explained that they would likely do the same things as their teachers. Johnny said that if he were a teacher, "If [students] score high or low on the benchmark [tests], they're bad and good, and I'd put them in groups with the benchmarks that they're - which they're struggling in." This is a practice commonly used in their classes. LaTonya explained, "I think I would give them stuff that related to the FCAT, so they could be more focused." The other students indicated their agreement. When asked what kind of "stuff," LaTonya replied, "I don't know - whatever's on the FCAT." Such comments indicated that this group of students believed that passing the FCAT was the primary reason for education. Data analysis revealed several instances where students agreed that preparing for the 
FCAT was the goal of their education in Reading. In all, the focus group interviews clearly indicated that the students perceived their Reading class largely in the context of a diagnostic testing situation. The quantitative phase of this study suggests that this may create an environment susceptible to stereotype threat.

Feelings of Stress and Anxiety Related to the State Test

The FCAT is the most important thing in the world. You can't even drop the thing! If you drop it, how you gonna breathe, man, how you gonna breathe!? (Floyd, African American fourth-grader)

In the quote above, Floyd vividly captures the focus group's feelings towards the FCAT. The focus group interviews revealed that the prospect of the upcoming state test made the students nervous to the point of negative physiological consequences. "I got butterflies in my stomach - it's going to feel like I got to go to the bathroom," Asia explained when asked how she felt about the proximity of the FCAT. Similarly, LaTonya explained, "I'm going to feel kind of nervous, I think I'm going to feel queasy." Floyd put it more vividly, "Like I feel nervous in my stomach, and this crazy sensation turning and turning. When your stomach is turning...it's turning so much, it turns into butter." Johnny insisted he wasn't the least bit nervous, at which point Asia and Floyd quickly reminded him that he always bites his nails before tests, to which he readily conceded his nervousness.

"If you weren't as nervous," LaTonya explained, “you wouldn't feel very—you wouldn't feel very, very sick." Quantitative results suggest that for stereotype-aware African American children, a significant level of pre-test anxiety was experienced only by the more highly domain-identified students. Qualitative findings complement these results with rich, thick description. Low self-efficacy, on the other hand, was not found to 
be a significant mediator quantitatively. Qualitative findings on the self-efficacy of this group of students were mixed. Some of these top performing students felt confident despite their nervousness. Johnny explained, "I feel confident. Because I feel nervous, but then I know that I'm going to do well on the thing." At the same time, others let their nerves affect their expectations, and expressed self-doubt. As an example, Floyd predicted he would fail, "That's why it's called the FCAT. It's spelled letters - and the first letter is an 'F."'

Data from focus group interviews also revealed that the students believed that they would not experience as much anxiety if the term "FCAT" was removed from the teachers' vocabularies. For example, LaTonya explained, "If I was a teacher, I wouldn't talk about the FCAT at all. I would scratch out the word 'FCAT' out of every test that [has] it... [the students] wouldn't be as nervous because they don't see the word "FCAT." Asia said that if she were a teacher, when the students were being tested she "would tell the kids that it's not an FCAT practice test, that it's just a regular test that we do. It would make things feel, like, less nervous." Her suggestion is consistent with quantitative results, which suggested that the performance of stereotype-aware African American students is depressed when the test was characterized as a diagnostic practice FCAT. In the quantitative phase of the study, stereotype-aware students performed better when the test was instead characterized as a nondiagnostic performance task. As it is presently, Asia explained, the practice tests are "putting too much pressure on your brain." Below she explains her theory on why mentioning the FCAT so much is detrimental to student performance: 
Like when the teachers say, "Okay kids, it's time to take the test, you have to get ready for the FCAT," they be like, "the FCAT!?" and that's when they whisper, "Are you nervous?"

"No, are you?"

"Yeah!"

And then, that puts a lot of pressure on their brain and they won't focus on the practice. Then, if they don't do well on the practice, why are they gonna do it on the FCAT? Because when they get pressure, they might get a question wrong, and then they might get most of the questions wrong.

As NCLB is further operationalized in low performing schools, the pressure on children is increased, and test anxiety can be expected to worsen. This phenomenon has a disproportionate effect on children of color. Students are pressured to do well on state tests as determinants of school funding. Qualitative data here supports past research (e.g., Townsend, 2002) indicating that particularly for African American students feelings of anxiety can be tied to their perceived failure. Analyses of focus group interviews made it clear that a theme of stress and anxiety became particularly salient with any discussion of the state test, particularly in reference to the perception that passing the test was the purpose for education. Findings from the quantitative phase of the study coupled with qualitative findings suggest that high-performing African American students become particularly anxious when faced with high-stakes testing, and that this anxiety is detrimental to performance.

\section{Concern with What "Others" Think (Racial Salience)}

"White people gonna be thinking that it's just an F. White people gonna be thinking maybe to themselves, 'Forever, [our school] is gonna get an F..." (Asia, African American fourth-grader) 
The academic achievement of African American students has often been associated with racial identity salience (Brown \& Pinel, 2003; Davis et al., 2006; Fordham \& Ogbu, 1986; Townsend, 2002). NCLB initiatives label schools as lowperforming based on standardized test scores. In Florida, schools are graded A through F based on these standards. Because African American children are enrolled predominantly in the schools labeled $\mathrm{D}$ or $\mathrm{F}$, such practices may jeopardize healthy racial identity development for these students. Analyses of the focus group interviews revealed that the students expressed a high level of concern about what other people might think about their school, especially outsiders. "They think that it's a boongy school!" Asia immediately expressed upon being confronted with this question. Later Johnny explained, “"boongy’ means lame, suckish.” Further analyses indicated that race was an integral factor in these perceptions. It was salient for the students that many people from outside the area, who were probably White, fostered negative opinions toward their school. "Black people," on the other hand, Johnny said, "think that we are going to bring [our school] to the top." The students agreed, and expressed a belief that White people held negative opinions about them because of the school's test scores. Floyd explained, "They think it because it's a D school, and going to an F." LaTonya agreed with Floyd's statement, "Because... this is a D school, people might think it's bad. They might think we have a lot of fights and stuff. They think that you dumb, and you fight a lot." Also, Johnny explained, "White people... they might think that since we a D school, we might be writing on the walls. We might be writing cuss words on the walls." 
Further analyses revealed that the students' beliefs about White people's perceptions were bothersome to them. Asia explained, "I think it's bad because they're talking about my school, the school where I go to, and if they talking about my school, that offends me." LaTonya offered, "It makes me feel kind of sad because - well it kind of makes me a little mad because just because I go to a D school, that does not mean that I'm a D student, or a D average student." These remarks are consistent with stereotype threat theory; the students expressed a desire to not confirm negative stereotypes against them. Steele (1997) explains that when individuals from stigmatized groups are placed in a situation where stereotypes about them become salient or relevant (whether or not they believe the stereotype to be true), efforts to disprove the stereotype can be debilitating.

For the students, race became salient in their perceptions of others' opinions about their school. Perceptions of others' opinions is the mechanism behind stereotype threat. Data from the focus group interviews revealed the students' awareness of how easily outsiders can find information to develop negative opinions towards them. The local newspaper publishes state test scores every year, and this information is easily found online. The fact that they attended a D school was salient. "Have you seen the grade on this school?" Floyd asked. "They have the grade right on top of the school... What if they put a 'D' right on top of the roof of the school, and helicopters could see it!' A D on the roof of the school visible from helicopters is a vivid metaphor for how the students feel their school grades are broadcast. Johnny explained that when someone looks at their school online, they can also find information about the school's "population." He said, “it's on the Internet. You go to - you see schools and everything, and then you see this school, you see the grade, and then you see where it's at, the population." The area 
surrounding the school is low-income and largely African American. Asia continued, “They might think, let me see your address, you don't go to an A [school] because you should be at [a low performing school]." Johnny's quote typifies how race was referred to in discussions: "There's some White people that are still angry with Black people...they still are hating Black people, so they still think that Black people are stupid and dumb." LaTonya chimed in that those White people get those ideas "from their negative brain." The school's test scores and school grade made race a salient factor for this group of students.

\section{Stereotypes}

The kids are from the streets. They act like little thugs. (Johnny, African American fourth-grader)

Data analysis revealed race became a salient part of discussions on standardized test scores. Additionally, although race was not always directly mentioned, race-based stereotypes were also a salient part of these discussions. Most often, the focus group made it a point to repudiate many stereotypes of their school. "Just because [some students at our school] wear pants below they waist, that doesn't mean they have to get a bad grade," Asia commented when asked to elaborate about what outsiders thought about her peers. The wearing of pants below the waist is a common style of dress for African American boys in their school. "I have a cousin in senior high school. Even though he wear his pants below his waist, he still do good," she added. The students nodded and yelled "yeah" in agreement. At least in part, the participants put the responsibility upon themselves for raising the school grade, and positively changing these stereotypes. "I'm trying to bring the scores of my school up, man!" Floyd said adamantly. "We want our 
school grades to come up so [we] are going to put maximum effort into this FCAT," Johnny explained. He expressed that this was counter to what the outside world believed about them: "I don't know what they think, but [doing well in school] will help me with my life, so when I get to college, I can do the four years, get my degree; I'll go on and be whatever I want to be." Not only did the students express the normal stress and anxiety associated with the high-stakes tests, these highly domain-identified students felt the extra burden of saving their school. Asia said clearly, "we are going to put maximum effort because ...[we] don't want the school to be teared down." A nearby elementary school was recently shut down by the state for consecutive years of poor test scores. At the same time, however, further analyses revealed that the focus group sometimes perpetuated negative race-based stereotypes onto students in neighboring schools. Johnny's quote above was about students in the neighboring elementary school. The school's demographics are almost identical to Johnny's. The kids there, LaTonya explained, "They are very bad and misbehaving." The "kind" of students that don't do well, Johnny explained, are "ones who wear their pants below their waist—pants be hanging, and boxers be showing." Interestingly, this was exactly the same stereotype they repudiated as not indicative of failure for the students in their school. None of the students reported ever being to the neighboring elementary school. LaTonya explained that whereas D and F schools (their school is a D school) "have kinda tough kids and gang bangers, 'good' schools have nice clothes, nice shoes, nice supplies." Ironically, data from the later focus group interviews indicated that students shared some beliefs in negative stereotypes about their school. Asia asked, "Have you seen the kids here? It's bad - like, 'I don't care about no FCAT.'” The interviews suggest that students have 
internalized some of the stereotypes they struggle against. As Asia's quote indicates, such beliefs can be tied to their perceived failure on state assessment measures. 


\section{CHAPTER V \\ DISCUSSION}

This chapter begins with a summary of the study, including an overview of significant findings. The summary is followed by a post-analysis of the conceptual model that guided the research and hypotheses, and the subsequent introduction of a new conceptual model based on the findings. The presentation of the new conceptual model is followed by an evaluation of findings with respect to prior research, a discussion of implications for both practice and policy, a discussion of the limitations, and recommendations for future research.

The current study was designed to qualify the value of stereotype threat theory, in a population of African American elementary school students in an urban community. Results of the current study indicate that the stereotype threat condition evoked by diagnostic testing depresses the reading test performance of stereotype-aware African American children. This was particularly true of students who are most highly domainidentified with reading. Moreover, findings indicated that only stereotype-aware African American children who were highly domain-identified were more likely to experience anxiety in the diagnostic condition. The qualitative phase of the current study complemented the quantitative phase by providing firsthand insight into the stereotype threat-associated standardized testing experiences of these highly domain-identified students that may lead to depressed performance and anxiety. Findings revealed that the students held a fundamental perception of education as test preparation. Findings also revealed that the school's focus on a test prep pedagogy (Rodríguez, 2008a) made racial stereotypes salient for the students. Efforts to disprove these stereotypes by "bringing the 
school up" are a fundamental part of the mechanisms of stereotype threat. Overall, the current study suggests that negative racial stereotypes regarding academic performance appear to become salient and have adverse effects on academic performance at early ages. These results may be particularly important to policymakers and educators in the wake of No Child Left Behind (NCLB) and its policies concerning standardized assessment as a tool for accountability and performance.

\section{A New Conceptual Model}

The present research and the hypotheses were based on a conceptual model developed from previous research (see Figure 1). Although some of the original hypotheses were confirmed, others were not. Findings therefore led to the development of a new conceptual model (see Figure 8). Findings from the current study suggest that awareness of a relevant negative stereotype is a prerequisite of stereotype threat experiences, and that stereotype-aware African American elementary school students who are highly domain-identified are more likely to experience stereotype threat in a diagnostic reading test situation. Experiencing stereotype threat has been linked to orientation towards performance-avoidance achievement goals (Ryan \& Ryan, 2005), and thereby anxiety (Elliot \& McGregor, 1999, 2001; Elliot et al., 1999; McGregor \& Elliot, 2002; Middleton \& Midgley, 1997; Skaalvik, 1997) and decreased self-efficacy (Middleton \& Midgley; Skaalvik). However, in the present study, quantitative results revealed no evidence of stereotype threat being characterized by a performance avoidance achievement goal orientation. Quantitative findings did suggest, though, that the stereotype threat experience may be mediated by increased pre-test anxiety, such that for highly domain-identified stereotype-aware students, significantly more pre-test 
anxiety is experienced when the test was presented as diagnostic as compared to when it was presented as nondiagnostic. The qualitative phase complemented these results by providing rich description from student perspectives. Students vividly described the anxiety in terms of negative physical consequences, and for some it led to decreased selfefficacy. Additionally, qualitative data revealed that for these children, the stereotype threat experience was characterized by racial identity salience brought about by diagnostic testing. Racial identity salience manifested itself largely in the context of participants' awareness of stereotypes held against them. All participants expressed the pressure of repudiating these stereotypes by scoring well on tests and lifting their school.

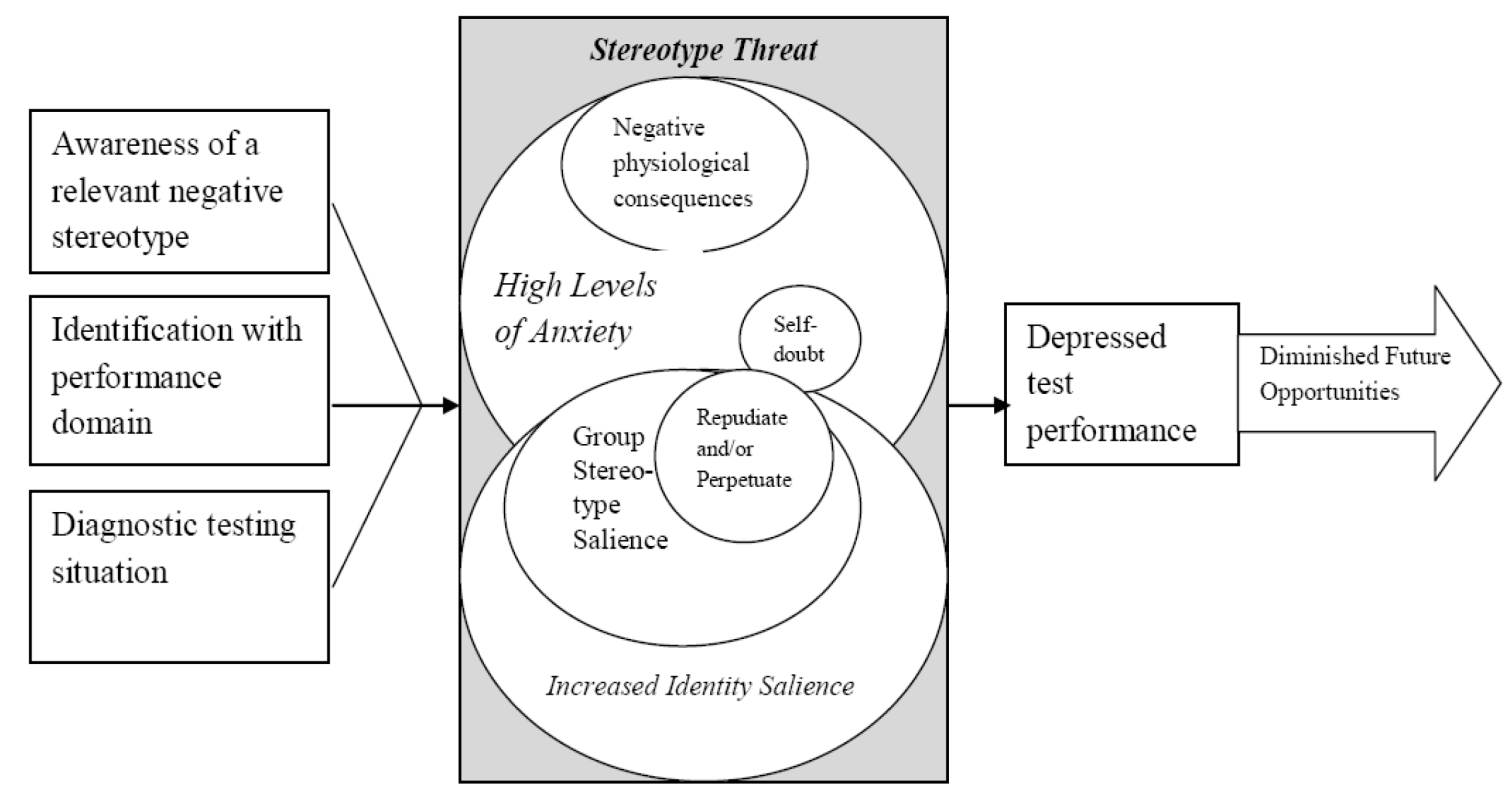

Figure 8. A new conceptual model for stereotype threat.

Some also expressed partial belief of the stereotypes. In combination, the present research demonstrates how these factors lead to depressed test performance for top performing 
stereotype-aware African American elementary school students. In the NCLB era, these test scores often have a direct influence on future opportunity for students.

The present research demonstrates how the mandated focus on diagnostic test preparation may particularly result in depressed performance for stereotype-aware African American children. This is disconcerting in that research demonstrates that as many as $93 \%$ of students from stigmatized groups may be stereotype-aware by age 10 (McKown \& Weinstein, 2003, Study 1). In the present study, 41\% of African American third-graders, $53 \%$ of fourth-graders, and 51\% of fifth-graders were found to be stereotype-aware. The slight drop in percentage from fourth to fifth grade may be due to the smaller sample size of fifth grade students, or to the fact that the ages of students were not recorded (some students had been retained, so some fourth graders were the same age as fifth graders). Additionally, the percentage of stereotype-aware students may be lower than found elsewhere because, unlike other studies, the present study utilized a sample of students from an urban environment with limited means of exposure to diversity. ${ }^{2}$ Nonetheless, to be sure, the percentage of stereotype-aware students will inevitably increase as students grow older and have more interactions with society. Interventions are therefore beneficial to all students.

Importantly, what seemed to expose this population to the effects of stereotype threat was not a weak academic identity, but instead stronger academic identity and skills. This is similar to what has been discovered in college populations (Steele, 2003). As Steele (1999, p. 49) puts it, "Black students taking the test under stereotype threat

\footnotetext{
${ }^{2}$ In the McKown and Weinstein (2003) study, for example, the majority of the students had parents with a college degree, and a large number were enrolled in gifted programs.
} 
seemed to be trying too hard rather than not hard enough." In his study with college students, African American participants re-analyzed the questions and their answers significantly more when they were under diagnostic conditions than when they were not, rendering them inefficient (Steele, 2003). It is possible that the same occurred in the present study with elementary aged participants. It seems that the specific effort associated with stereotype threat, the effort that Floyd associates repudiating stereotypes when he says, "I'm trying to bring the scores of my school up, man!" may be counterproductive. Although this is disheartening, the following implications sections offer research-based suggestions on what can be done to overcome the detrimental effects.

\section{Implications for Educators}

The present study suggests that test performance is sensitive to processes amenable to teacher intervention. This is of particular importance to teachers of African American children in that attention to the environmental details surrounding standardized testing situations can potentially prevent maladaptive consequences for their students. This study, among others (McKown \& Weinstein, 2003; Steele \& Aronson, 1995), has demonstrated that reframing a test as nondiagnostic can mitigate negative consequences for African American students in experimental conditions. However such recharacterization is not always practical in a real-world setting. This is especially difficult in schools housing predominantly African American populations where diagnostic testing protocols often dominate the curriculum.

The student-teacher relationship is integral in providing a solution for the negative consequences of stereotype threat. Steele (2003) explains that African American college 
students performed well on a diagnostic test, regardless of previous negative experiences, only when they felt trust. Without trust, no techniques to boost self-esteem worked. Much of the dominant dialogue surrounding African American academic underperformance utilizes cultural-deficit (e.g., Thernstrom \& Thernstrom, 2003) and even genetic-deficit (e.g., Herrnstein \& Murray, 1994) models. Manifestly, educators who wear this theoretical lens are unlikely to gain the trust of their African American students. Conversely, the present study suggests that high performing African American students express the desire and ability to achieve, while wearing the burden of negative societal stereotypes. "I don't know what they think," Johnny said, "but [doing well in school] will help me with my life, so when I get to college, I can do the 4 years, get my degree; I'll go on and be whatever I want to be." Future research is necessary to further investigate the relationship between student-teacher relationships, particularly at the elementary level, and stereotype threat.

In the context of school improvement, little attention is placed on the development of trusting relationships between students and teachers. This is especially important in urban schools where the majority of teachers come from a different cultural background than the students (NCES, 2009). Students from urban environments highlight the importance of recognition by school adults (Rodríguez, 2008b). Trust-based studentteacher relationships have a direct positive effect on student academic achievement (Bryk \& Schneider, 2002). Delpit (2006) puts it eloquently when she states:

I have discovered that children of color, particularly African American, seem especially sensitive to their relationship between themselves and their teacher. I have concluded that it appears that they not only learn from a teacher but also for a teacher. If they do not feel connected to a teacher on an emotional level, then they will not learn, they will not put out the effort. (p. 227) 
As a teacher for several years in an urban school, the author's experiences concur with those of Delpit. Even for well-intentioned teachers, however, such relationships may be more difficult to develop when the teacher must follow test-practice protocols, which limit meaningful dialogue. The present study contributes to the research by challenging intellectual paradigms based on a deficit theoretical lens. The burden for student success must be placed, at least in part, on the willingness of teachers to develop trusting relationships with their students. Experimentally, invoking "high standards" was enough to evoke trust in African American college students that academic evaluation was not based on race, thereby reducing the effects of stereotype threat (Cohen et al., 1999). More than that is likely necessary at the elementary level.

Additionally, positive intervention has already been demonstrated in college populations by teaching stereotype threat (Johns et al., 2005) and blurring intergroup boundaries (Rosenthal \& Crisp, 2006). Positive intervention has been demonstrated in both middle school and college populations by teaching students to view intelligence as malleable rather than fixed (Aronson et al., 2002; Good et al., 2003), by having students reaffirm their sense of self-worth (Cohen et al., 2006; Cohen, Garcia, Purdie-Vaughns, Apfel, \& Brzustoski, 2009; Martens et al., 2006), and by providing access to positive ingroup role models (Huguet \& Regner, 2007; Marx, Ko, \& Friedman, 2009; Marx \& Roman, 2002). If educators are interested in ameliorating the racial test score gap, implementation of interventions to help prevent the negative performance consequences evoked by stereotype threat is essential at earlier ages. Therefore, future research in an elementary school setting examining the effects of these interventions on academic 
performance is critical. The author suggests interventions focused on the relationship between students and teachers.

$$
\text { Implications for Policy }
$$

This research also has important implications for educational policy. Findings provide important information for policymakers about how standardized testing based curricula may undermine the achievement of certain student populations. NCLB professes an aim of addressing the racial "achievement gap," and articulates an emphasis on high achievement for all students. The legislation aims to achieve this goal primarily through increased accountability measured by standardized testing. However, the implementation of high-stakes testing regimens may be having adverse effects on certain populations of students, as pedagogies based on relationship-building are almost nonexistent for the instruction of many African American students. The present research bolsters the argument that high-stakes standardized testing situations make relevant social stereotypes salient, thereby depressing the academic performance in African American populations. Thus, attention to the situational presentation of testing is critical. Such information is of particular importance to educational policymakers.

NCLB has substantially increased the importance of standardized testing in determinations of school funding (U.S. Department of Education, 2007). Schools in Florida, for example, are assigned a letter grade (A through F) determined by Florida Comprehensive Assessment Test (FCAT) scores. Letter grade gains, or maintenance of high achievement, may result in salary bonuses for teachers and administrators. School improvement, from the perspective of state and federal policymakers, is defined as increased test scores. Teachers and administrators are forced to facilitate this 
improvement, and as a result, standardized tests inherently control curricular choices, as "teaching to the test" becomes an often necessary prerequisite for increased funding. As evidenced in this study and elsewhere (e.g. Cawelti, 2006; Kozol, 2005), this has lead to an unbalanced focus on test practice material, especially in elementary schools serving African American students, as well as a tendency for students to perceive the educational process as nothing more than test preparation. This was illustrated by Latonya's comment when asked what she would teach if she were the teacher. She responded, "I don't know - whatever's on the FCAT."

The present research is indicative that African American elementary school students are negatively affected by this shift towards mandated focus on testing. Increased importance of diagnostic testing heightens stereotype salience, and depresses the performance of the best performing students from what NCLB calls "low-performing subgroups." Past research demonstrates that when a particular identity of an individual is directly made salient, his or her performance alters in the direction of associated relevant stereotypes (Shih et al., 1999). State-mandated scripted curricular programs are overwhelmingly implemented in schools serving African American children. As an illustrative example, White children make up only about one percent of students in New York City in which such instruction was imposed (Kozol, 2005). ${ }^{3}$ This is a testament to public school inequalities in the United States. As a result, as affirmed by students in this study, social studies and the arts are pushed to the margins of the curriculum, regarded as distractions from what will be tested. Often, district officials visit schools to make sure

\footnotetext{
${ }^{3}$ Ironically, brochures advertising such curricula show happy racially integrated classrooms (e.g. Acaletics, 2008; Plato Learning, 2008; Rocket Learning, 2008; Voyager Learning, 2008)).
} 
the scripted plan is in place. During the present study, on two occasions over the course of 30 visits, the researcher was denied access to the classroom because of district-level visitations. As a urban elementary school teacher, the author has experienced these visits several times. Increased monitoring and further guidance is often insisted for teachers who have "strayed" off scripted lessons and taken advantage of teachable moments. Social studies achievement cannot contribute to a school's state ranking. The academic detriment of the subsequent marginalization of this subject is a side effect either unnoticed or ignored by policymakers. Kozol (2005) recalls a discussion with sixthgraders for whom social studies had been replaced by state test practice:

...I was surprised when I was asked if "Massachusetts," which the children knew is where I live, was "in New York."...I tried to do a little lesson with them about cities, states, and countries, but I recognized that these distinctions were not clear to them at all... Whether the life of Martin Luther King came after, or before, the War Between the States or the War of Independence or, for that matter, the year when they were born was all a hopeless blur. (pp.118-119)

This is in line with the "we don't do social studies anymore" comment from the present study. Such situations are crippling already marginalized students. This largely African American population is being taught to pass a state exam, while basic aesthetic, geographic, and historic knowledge has been systematically eliminated from the curriculum at their schools.

As evidenced in this study, some affected students have come to view education as test preparation. In addition, instructional time has been minimized even in tested areas. The participants in the qualitative phase of this study explain how their school administers several additional pre-, mid-, and post-tests in all areas to document to the district and state that their implemented curriculum is having the desired effect. 
Administering such tests to an entire student body, their subsequent scoring, and the mandated data analysis regularly eliminates a week of instructional time at least three times per year. It seems that the mandates of NCLB have popularized this approach in the United States. As Kozol (1992) puts it,

They do not learn to think, because the teachers are straightjacketed by tests that measure only isolated skills. As a result, they can be given...nothing wonderful or fanciful or beautiful, nothing that touches the spirit or soul. Is this what the country wants for its black children? (p.119)

The denial of aesthetics and basic content knowledge to African American children, however, is unmentioned when legislators boast how their policies have increased standardized test scores for this population. Based upon the above argument, teachers and administrators at these schools are financially rewarded for this denial.

In addition to the negative effects on children evidenced here, the teachers in lowincome schools are less likely than their counterparts in high-income schools to have a curriculum that is flexible for use in the classroom to meet individual student needs. These teachers are significantly more likely to report using rote-based directive reading curriculum that provides scripted lesson plans (Johnson et al., 2004). It has thus been established that helping children increase their test scores has taken precedence over facilitating a more engaged level of learning for all children in our low-income, predominantly African American and Latino, public schools. Some teachers have followed the scripts willingly, in search of external praise, or convinced that "these kids need this" (Crawford, 2004, p. 209). Others have reluctantly done so in silent protest, wanting what is best for their children, but not wanting to risk their jobs. Based on 
present curricular mandates, whether or not curricular models cause student disengagement seems unimportant to policymakers.

Not only do the test-preparation curricular models inevitably streamline the curriculum to only include tested areas, teachers are often deprofessionalized to the point of following a "test-prep" script. Berliner and Biddle (1995) put it well when they say that these programs seem to generate "the three A's, Anxiety, Anger, and Alienation." As a whole, second-year elementary teachers in low-income schools report having too little freedom to determine what and how to teach in higher proportions than their counterparts in high-income schools. Also contributing to teacher anxiety is a high level of dissatisfaction with test preparation curricular materials (Kauffman et al., 2002), and a reduction in their sense of professional control (Lutz \& Maddirala, 1990). The present study suggests that this anxiety surrounding the standardized test is being passed on to students. This seems particularly true for African American students contending with negative stereotypes surrounding their test performance.

NCLB legislation is inherently forcing educators to reduce curriculum, impose rote methods of test preparation, and lose their professional enthusiasm (Ahlquist, 2003; Costigan et al., 2004; Kozol, 2005; Meier \& Wood, 2004). Whereas high-quality teachers at many privileged schools throughout our nation are presenting their most creative lessons when being observed by superiors, teachers at low-income urban schools are presenting their most scripted (Saltman \& Gabbard, 2003). Quality teaching has been externally redefined in such schools. If policymakers are interested in working to counter the detrimental stereotype threat effects surrounding diagnostic testing on African American children delineated in the present study (e.g., depressed academic performance 
in diagnostic testing situations), it seems the power to initiate such reforms should be concentrated at the classroom level and in the hands of the local community and professional educators themselves. These educators are likely the most familiar with the contextual circumstances surrounding testing in their classrooms. This is important in an effort to eliminate a threatening environment that may depress test performance. This study adds to literature delineating the need for a true reform.

\section{Limitations of the Study}

The student sample was not randomly selected and therefore results cannot be generalized to the entire population of African American elementary school students. Additionally, to the author's knowledge the Domain Identification Measure has never been utilized on a child sample, and the psychometrics have not been analyzed for children.

\section{Future Directions}

Future directions should include testing the effectiveness of interventions to help prevent the negative performance consequences evoked by stereotype threat at earlier ages. This should include research in an elementary school setting, and examining the effects of these interventions on academic performance. As delineated above, the author suggests interventions focused on the relationship between students and teachers. In addition, it seems likely that children aware of stereotypes will experience stereotype threat effects in a range of situations beyond standardized tests. Future research should examine the cognitive processes at work, and the consequences of stereotype threat effects, outside this particular domain. 


\section{REFERENCES}

Acaletics (2008). Acaletics by Educational Development Associates, Inc. Success in partnerships. Retrieved November 6, 2008, from http://www.acaletics.com/press.htm

Ahlquist, R. (2003). Challenges to academic freedom: California teacher educators mobilize to resist state-mandated control of the curriculum. Teacher Education Quarterly, 30(1), 57-64.

Ambady, N., Paik, S. K., Steele, J., Owen-Smith, A., \& Mitchell, J. P. (2004). Deflecting negative self-relevant stereotype activation: The effects of individuation. Journal of Experimental Social Psychology, 40(3), 401-408.

Ambady, N., Shih, M., Kim, A., \& Pittinsky, T. L. (2001). Stereotype susceptibility in children: Effects of identity activation on quantitative performance. Psychological Science, 12, 385-390.

Ames, C. (1992). Classrooms: Goals, structures, and student motivation. Journal of Educational Psychology, 84(3), 261-271.

Aronson, J., Fried, C. B., \& Good, C. (2002). Reducing the effects of stereotype threat on African American college students by shaping theories of intelligence. Journal of Experimental Social Psychology, 38, 29-46.

Aronson, J., Lustina, M. J., Good, C., Keough, K., Steele, C. M., \& Brown, J. (1999). When white men can't do math: Necessary and sufficient factors in stereotype threat. Journal of Experimental Social Psychology, 35, 29-46.

Aronson, J., Quinn, D. M., \& Spencer, S. J. (1998). Stereotype threat and the academic underperformance of minorities and women. In J. K. Swim \& C. Stangor (Eds.), Prejudice: The target's perspective (pp. 83-103). New York: Academic Press.

Berliner, D. C., \& Biddle, B. J. (1995). The manufactured crisis: Myths, fraud, and the attack on America's public schools. Reading, MA: Addison-Wesley.

Betz, N. E., \& Hackett, G. (1983). The relationship of mathematics self-efficacy expectations to the selection of science-based college majors. Journal of Vocational Behavior, 23(3), 329-345.

Biek, D. M. (2006). Stereotype threat and domain identification. Unpublished Ph.D., Cornell University, Ithaca, NY.

Blascovich, J., Spencer, S. J., Quinn, D., \& Steele, C. (2001). African Americans and high blood pressure: the role of stereotype threat. Psychological Science, 12, $225-$ 229. 
Bogdan, R. C., \& Biklen, S. K. (2003). Qualitative research for education: An introduction to theories and methods (4th ed.). New York: Pearson.

Bong, M., \& Skaalvik, E. M. (2003). Academic self-concept and self-efficacy: How different are they really? Educational Psychology Review, 15(1), 1-40.

Bosson, J. K., Haymovitz, E. L., \& Pinel, E. C. (2004). When saying and doing diverge: The effects of stereotype threat on self-reported versus non-verbal anxiety. Journal of Experimental Social Psychology, 40, 247-255.

Brown, R. P., \& Pinel, E. C. (2003). Stigma on my mind: Individual differences in the experience of stereotype threat. Journal of Experimental Social Psychology, 39(6), 626-633.

Bryk, A. S., \& Schneider, B. L. (2002). Trust in schools: A core resource for improvement. New York: Russell Sage Foundation Publications.

Cadinu, M., Maass, A., Frigerio, S., Impagliazzo, L., \& Latinotti, S. (2003). Stereotype threat: The effect of expectancy on performance. European Journal of Social Psychology, 33(2), 267-285.

Cawelti, G. (2006). The side effects of NCLB. Educational Leadership, 64(3), 64-685.

Cohen, G. L., Garcia, J., Apfel, N., \& Master, A. (2006). Reducing the racial achievement gap: A social-psychological intervention. Science, 313(5791), 1307.

Cohen, G. L., Garcia, J., Purdie-Vaughns, V., Apfel, N., \& Brzustoski, P. (2009). Recursive processes in self-affirmation: Intervening to close the minority achievement gap. Science, 324(5925), 400.

Cohen, G. L., Steele, C. M., \& Ross, L. D. (1999). The mentor's dilemma: Providing critical feedback across the racial divide. Personality and Social Psychology Bulletin, 25(10), 1302-1318.

College Board (2006). College Board National Report. 2006 College bound seniors: Total group profile report. Retrieved July 9, 2007, from http://www.collegeboard.com/prod_downloads/about/news_info/cbsenior/yr2006/ national-report.pdf

Costigan, A. T., Zumwalt, K. K., Crocco, M., \& Gerwin, D. M. (2004). Learning to teach in an age of accountability. Mahwah, NJ: Lawrence Erlbaum Associates.

Crawford, P. A. (2004). "I follow the blue:" A primary teacher and the impact of packaged curricula. Early Childhood Education Journal, 32(3), 205-210.

Creswell, J. W. (1994). Research design: Qualitative approaches. London: Sage Publications. 
Croizet, J. C., \& Claire, T. (1998). Extending the concept of stereotype threat to social class: The intellectual underperformance of students from low socioeconomic backgrounds. Personality and Social Psychology Bulletin, 24(6), 588-594.

Croizet, J. C., Despres, G., Gauzins, M. E., Huguet, P., Leyens, J. P., \& Meot, A. (2004). Stereotype threat undermines intellectual performance by triggering a disruptive mental load. Personality and Social Psychology Bulletin, 30(6), 721-731.

Dar-Nimrod, I., \& Heine, S. J. (2006). Exposure to scientific theories affects women's math performance. Science, 314(5798), 435-435.

Davis, C., Aronson, J., \& Salinas, M. (2006). Shades of threat: Racial identity as a moderator of stereotype threat. Journal of Black Psychology, 32(4), 399-417.

DeCuir, J. T., \& Dixson, A. D. (2004). "So when it comes out, they aren't that surprised that it is there": Using critical race theory as a tool of analysis of race and racism in education. Educational Researcher, 33(5), 26-31.

Delgado Bernal, D. (2002). Critical race theory, Latino critical theory, and critical racedgendered epistemologies: Recognizing students of color as holders and creators of knowledge. Qualitative Inquiry, 8(1), 105.

Delpit, L. (2006). Lessons from teachers. Journal of Teacher Education, 57(3), 220-231.

Denzin, N. K., \& Lincoln, Y. S. (Eds.). (2000). Handbook of qualitative research (2nd ed.). Thousand Oaks, CA: Sage Publications.

Dixson, A. D., \& Rousseau, C. K. (Eds.). (2006). Critical race theory in education: All God's children got a song. New York: Routledge.

Duncan, G. A. (2002a). Beyond love: A critical race ethnography of the schooling of adolescent Black males. Equity and Excellence in Education, 35(2), 131-143.

Duncan, G. A. (2002b). Critical race theory and method: Rendering race in urban ethnographic research. Qualitative Inquiry, 8(1), 85-104.

Dweck, C. S. (1986). Motivational processes affecting learning. American Psychologist, 41(10), 1040-1048.

Dweck, C. S., \& Leggett, E. L. (1988). A social-cognitive approach to motivation and personality. Psychological Review, 95(2), 256-273.

Elliot, A. J., \& McGregor, H. A. (1999). Test anxiety and the hierarchical model of approach and avoidance achievement motivation. Journal of Personality and Social Psychology, 76(4), 628-644. 
Elliot, A. J., \& McGregor, H. A. (2001). A 2 X 2 achievement goal framework. Journal of Personality and Social Psychology, 80(3), 501-519.

Elliot, A. J., McGregor, H. A., \& Gable, S. (1999). Achievement goals, study strategies, and exam performance: A mediational analysis. Journal of Educational Psychology, 91(3), 549-563.

Elliot, A. J., \& Sheldon, K. M. (1997). Avoidance achievement motivation: a personal goals analysis. Journal of Personality and Social Psychology, 73(1), 171-185.

Florida Department of Education (2006a). Florida Department of Education Media Packet. 2006 FCAT Reading and Mathematics. Retrieved July 9, 2007, from http://fcat.fldoe.org/pdf/mediapdf/FCAT_06_media_complete.pdf

Florida Department of Education (2006b). Technical Report for 2006 FCAT Test Administrators. 2006 FCAT Reading and Mathematics. Retrieved June 8, 2009, from http://fcat.fldoe.org/pdf/fc06tech.pdf

Ford, T. E., Ferguson, M. A., Brooks, J. L., \& Hagadone, K. M. (2004). Coping sense of humor reduces effects of stereotype threat on women's math performance. Personality and Social Psychology Bulletin, 30(5), 643-653.

Fordham, S., \& Ogbu, J. U. (1986). Black students' school success: Coping with the "burden of 'acting white'". The Urban Review, 18(3), 176-206.

Frantz, C. M., Cuddy, A. J. C., Burnett, M., Ray, H., \& Hart, A. (2004). A threat in the computer: The race implicit association test as a stereotype threat experience. Personality and Social Psychology Bulletin, 30(12), 1611-1624.

Gall, M. D., Gall, J. P., \& Borg, W. R. (2007). Educational research: An introduction (8th ed.). New York: Pearson.

Ginwright, S., Cammarota, J., \& Noguera, P. A. (2005). Youth, social justice, and communities: Toward a theory of urban youth policy. Social Justice, 32(3), 24-40.

Glaser, B. G., \& Strauss, A. L. (1967). A discovery of grounded theory: Strategies for qualitative research. Chicago: Aldine.

Gonzales, P. M., Blanton, H., \& Williams, K. J. (2002). The effects of stereotype threat and double-minority status on the test performance of Latino women. Personality and Social Psychology Bulletin, 28(5), 659-670.

Good, C., Aronson, J., \& Inzlicht, M. (2003). Improving adolescents' standardized test performance: An intervention to reduce the effects of stereotype threat. Journal of Applied Developmental Psychology, 24(6), 645-662.

Greene, J. C. (2007). Mixed methods in social inquiry. San Francisco: Jossey-Bass. 
Harrison, L. A., Stevens, C. M., Monty, A. N., \& Coakley, C. A. (2006). The consequences of stereotype threat on the academic performance of White and non-White lower income college students. Social Psychology of Education, 9(3), 341-357.

Herrnstein, R. J., \& Murray, C. (1994). The bell curve: Intelligence and class structure in American life. New York: Free Press.

Hilliard, A. G. (2003). No mystery: Closing the achievement gap. In T. Perry, C. Steele \& A. G. Hilliard (Eds.), Young, gifted, and Black: Promoting high achievement among African-American students. Boston: Beacon Press.

Huguet, P., \& Regner, I. (2007). Stereotype threat among schoolgirls in quasi-ordinary classroom circumstances. Journal of Educational Psychology, 99(3), 545-560.

Inzlicht, M., \& Ben-Zeev, T. (2000). A threatening intellectual environment: Why females are susceptible to experiencing problem-solving deficits in the presence of males. Psychological Science, 11, 365-371.

Inzlicht, M., \& Ben-Zeev, T. (2003). Do high-achieving female students underperform in private? The implications of threatening environments on intellectual processing. Journal of Educational Psychology, 95(4), 796-805.

Inzlicht, M., McKay, L., \& Aronson, J. (2006). Stigma as ego-depletion: How being the target of prejudice affects self-control. Psychological Science, 17, 262-269.

Jencks, C., \& Phillips, M. (Eds.). (1998). The Black-White test score gap. Washington, DC: Brookings.

Jimerson, S. R., Ferguson, P., Whipple, A. D., Anderson, G. E., \& Dalton, M. J. (2002). Exploring the association between grade retention and dropout: A longitudinal study examining socio-emotional, behavioral, and achievement characteristics of retained students. The California School Psychologist, 7, 51-62.

Johns, M., Schmader, T., \& Martens, A. (2005). Knowing is half the battle: Teaching stereotype threat as a means of improving women's math performance.

Psychological Science, 16(3), 175-179.

Johnson, S. M., Kardos, S. M., Kauffman, D., Liu, E., \& Donaldson, M. L. (2004). The support gap: New teachers' early experiences in high-income and low-income schools. Education Policy Analysis Archives, 12(61), 1-25.

Jordan, A. H., \& Lovett, B. J. (2007). Stereotype threat and test performance: A primer for school psychologists. Journal of School Psychology, 45(1), 45-59. 
Kauffman, D., Johnson, S., Kardos, S., Liu, E., \& Peske, H. (2002). "Lost at sea:" New teachers' experiences with curriculum and assessment. Teachers College Record, 104(2), 273-300.

Keller, J. (2007). Stereotype threat in classroom settings: The interactive effect of domain identification, task difficulty and stereotype threat on female students' maths performance. British Journal of Educational Psychology, 77(2), 323-338.

Keller, J., \& Dauenheimer, D. (2003). Stereotype threat in the classroom: Dejection mediates the disrupting threat effect on women's math performance. Personality and Social Psychology Bulletin, 29(3), 371-381.

Kozol, J. (1992). Savage inequalities: Children in America's schools. New York: HarperCollins.

Kozol, J. (2005). The shame of the nation: The restoration of apartheid schooling in America. New York: Crown Publishers.

Ladson-Billings, G. (1999a). Just what is critical race theory and what's it doing in a nice field like education? In L. Parker, D. Deyhle \& S. Villenas (Eds.), Race is... race isn't: Critical race theory and qualitative studies in education (pp. 7-30). Boulder, CO: Westview Press.

Ladson-Billings, G. (1999b). Preparing teachers for diverse student populations: A critical race theory perspective. Review of Research in Education, 24(21), 211247.

Ladson-Billings, G., \& Tate, W. F. (1995). Toward a critical race theory of education. Teachers College Record, 97(1), 47-68.

Leedy, P. E., \& Ormrod, J. D. (2005). Practical research: Planning and design (8th ed.). New Jersey: Prentice Hall.

Lesko, A. C., \& Corpus, J. H. (2006). Discounting the difficult: How high mathidentified women respond to stereotype threat. Sex Roles, 54(1), 113-125.

Leyens, J. P., Desert, M., Croizet, J. C., \& Darcis, C. (2000). Stereotype threat: Are lower status and history of stigmatization preconditions of stereotype threat? Personality and Social Psychology Bulletin, 26(10), 1189-1199.

Lopez, G. R. (2003). The (racially neutral) politics of education: A critical race theory perspective. Educational Administration Quarterly, 39(1), 68-94.

Lutz, F. W., \& Maddirala, J. (1990). Stress, burnout, in Texas teachers and reform mandated accountability. Educational Research Quarterly., 14(2), 10-21. 
Lynn, M., \& Adams, M. (2002). Introductory overview to the special issue critical race theory and education: Recent developments in the field. Equity and Excellence in Education, 35(2), 87-92.

Major, B., Spencer, S. J., Schmader, T., Wolfe, C., \& Crocker, J. (1998). Coping with negative stereotypes about intellectual performance: The role of psychological disengagement. Personality and Social Psychology Bulletin, 24(1), 34-50.

Martens, A., Johns, M., Greenberg, J., \& Schimel, J. (2006). Combating stereotype threat: The effect of self-affirmation on women's intellectual performance. Journal of Experimental Social Psychology, 42(2), 236-243.

Marx, D. M., Ko, S. J., \& Friedman, R. A. (2009). The "Obama Effect": How a salient role model reduces race-based performance differences. Journal of Experimental Social Psychology.

Marx, D. M., \& Roman, J. S. (2002). Female role models: Protecting women's math test performance. Personality and Social Psychology Bulletin, 28(9), 1183-1193.

Massey, D. S., \& Fischer, M. J. (2005). Stereotype threat and academic performance: New findings from a racially diverse sample of college freshmen. $D u$ Bois Review: Social Science Research on Race, 2(01), 45-67.

McGregor, H. A., \& Elliot, A. J. (2002). Achievement goals as predictors of achievement-relevant processes prior to task engagement. Journal of Educational Psychology, 94(2), 381-395.

McIntyre, R. B., Paulson, R. M., \& Lord, C. G. (2003). Alleviating women's mathematics stereotype threat through salience of group achievements. Journal of Experimental Social Psychology, 39(1), 83-90.

McKay, P. F., Doverspike, D., Bowen-Hilton, D., \& Martin, Q. D. (2002). Stereotype threat effects on the Raven Advanced Progressive Matrices scores of African Americans. Journal of Applied Social Psychology, 32(4), 767-787.

McKown, C., \& Weinstein, R. S. (2003). The development and consequences of stereotype consciousness in middle childhood. Child Development, 74(2), 498515 .

McMillan, J. H., \& Schumacher, S. (2001). Research in education: A conceptual introduction (5th ed.). New York: Longman.

Meier, D., \& Wood, G. (Eds.). (2004). Many children left behind: How the No Child Left Behind Act is damaging our children and our schools. Boston: Beacon Press.

Merriam, S. B. (Ed.). (2002). Qualitative research in practice. San Francisco, CA: Jossey Bass. 
Miami-Dade County Public Schools (2006). MDCPS District and School Profiles. 20052006 District and School Profiles. Retrieved November 27, 2007, from http://oada.dadeschools.net/DSProfiles/0506Profiles.asp

Middleton, M. J., \& Midgley, C. (1997). Avoiding the demonstration of lack of ability: An underexplored aspect of goal theory. Journal of Educational Psychology, 89(4), 710-718.

Midgley, C., Maehr, M., Hicks, L., Roeser, R., Urdan, T., Anderman, E., et al. (1996). Patterns of adaptive learning survey (PALS). Ann Arbor, MI: Center for Leadership and Learning, University of Michigan.

Midgley, C., Maehr, M. L., Hruda, L. Z., Anderman, E., Anderman, L., Freeman, K. E., et al. (2000). Manual for the Patterns of Adaptive Learning Scales. Ann Arbor, MI: University of Michigan.

Milner, H. R., \& Hoy, A. W. (2003). A case study of an African American Teacher's selfefficacy, stereotype threat, and persistence. Teaching and Teacher Education, 19(2), 263-276.

Nasir, N. S., \& Hand, V. M. (2006). Exploring sociocultural perspectives on race, culture, and learning. Review of Educational Research, 76(4), 449-475.

National Center for Educational Statistics [NCES] (2007). National Center for Educational Statistics. Nation's Report Card. Retrieved November 24, 2007, from http://nces.ed.gov/

National Center for Educational Statistics [NCES] (2009). National Center for Educational Statistics. Overview of Public Elementary and Secondary Schools and Districts: School Year 2001-2002. Retrieved July 23, 2009, from http://nces.ed.gov/

Noguera, P. A. (1996). Responding to the crisis confronting California's Black male youth: Providing support without furthering marginalization. The Journal of Negro Education, 65(2), 219-236.

Noguera, P. A. (2003). City schools and the American dream. New York: Teachers College Press.

Ogbu, J. U. (1983). Minority status and schooling in plural societies. Comparative Education Review, 27(2), 168-190.

Ogbu, J. U. (1986). The consequences of the American caste system. In U. Neisser (Ed.), The school achievement of minority children: New perspectives (pp. 19-56). Hillsdale, NJ: Erlbaiam. 
Osborne, J. W. (1997). Race and academic disidentification. Journal of Educational Psychology, 89(4), 728-735.

Osborne, J. W. (2001). Testing stereotype threat: Does anxiety explain race and sex differences in achievement? Contemporary Educational Psychology, 26(3), 291310 .

Papay, J., \& Hedl, J. (1978). Psychometric characteristics and norms for disadvantaged third and fourth grade children on the State-Trait Anxiety Inventory for Children. Journal of Abnormal Child Psychology, 6(1), 115-120.

Papay, J., \& Spielberger, C. (1986). Assessment of anxiety and achievement in kindergarten and first-and second-grade children. Journal of Abnormal Child Psychology, 14(2), 279-286.

Parker, L., Deyhle, D., \& Villenas, S. (Eds.). (1999). Race is... race isn't: Critical race theory and qualitative studies in education. Boulder, CO: Westview Press.

Parker, L., \& Lynn, M. (2002). What's race got to do with it? Critical race theory's conflicts with and connections to qualitative research methodology and epistemology. Qualitative Inquiry, 8(1), 7-22.

Parker, L., \& Stovall, D. O. (2004). Actions following words: Critical race theory connects to critical pedagogy. Educational Philosophy and Theory, 36(2), 167182.

Perry, T. (2003). Up from the parched earth: Toward a theory of African-American achievement. In T. Perry, C. Steele \& A. G. Hilliard (Eds.), Young, gifted, and Black: Promoting high achievement among African-American students (pp. 1108). Boston: Beacon Press.

Pintrich, P. R. (2000). An achievement goal theory perspective on issues in motivation terminology, theory, and research. Contemporary Educational Psychology, 25(1), 92-104.

Plato Learning (2008). Plato Learning. Plato K-6 prescriptive learning solution. Retrieved November 6, 2008, from http://www.plato.com

Rivadeneyra, R. (2006). Do you see what I see?: Latino adolescents' perceptions of the images on television. Journal of Adolescent Research, 21(4), 393-414.

Roberts, N., Vargo, B., \& Ferguson, H. (1989). Measurement of anxiety and depression in children and adolescents. The Psychiatric Clinics of North America, 12(4), 837860 .

Rocket Learning (2008). Rocket Learning. Impact on teachers. Retrieved November 6, 2008, from http://www.rocketlearning.net 
Rodríguez, L. F. (2008a). "I've never heard of the word pedagogy before": Using liberatory pedagogy to forge hope for new teachers in our nation's public schools. InterActions: UCLA Journal of Education and Information Studies, 4(2), http://repositories.cdlib.org/gseis/interactions/vol4/iss2/art2.

Rodríguez, L. F. (2008b). Struggling to recognize their existence: Examining studentadult relationships in the urban high school context. The Urban Review, 40(5), $436-453$.

Rosenthal, H. E. S., \& Crisp, R. J. (2006). Reducing stereotype threat by blurring intergroup boundaries. Personality and Social Psychology Bulletin, 32(4), 501511.

Ryan, K. E., \& Ryan, A. M. (2005). Psychological processes underlying stereotype threat and standardized math test performance. Educational Psychologist, 40(1), 53-63.

Saltman, K. J., \& Gabbard, D. (Eds.). (2003). Education as enforcement: The militarization and corporatization of schools. New York: RoutledgeFalmer.

Schmader, T. (2002). Gender identification moderates stereotype effects on women's math performance. Journal of Experimental Social Psychology, 38, 194-201.

Shapiro, J. R., \& Neuberg, S. L. (2007). From stereotype threat to stereotype threats: Implications of a multi-threat framework for causes, moderators, mediators, consequences, and interventions. Personality and Social Psychology Review, 11(2), 107-130.

Shepard, L. A., \& Smith, M. L. (Eds.). (1989). Repeating and dropping out of school. Breistol, PA: Falmer Press.

Shih, M., Bonam, C., Sanchez, D., \& Peck, C. (2007). The social construction of race: biracial identity and vulnerability to stereotypes. Cultural Diversity and Ethnic Minority Psychology, 13(2), 125-133.

Shih, M., Pittinsky, T. L., \& Ambady, N. (1999). Stereotype susceptibility: Identity salience and shifts in quantitative performance. Psychological Science, 10(1), 8083.

Skaalvik, E. M. (1997). Self-enhancing and self-defeating ego orientation: Relations with task and avoidance orientation, achievement, self-perceptions, and anxiety. Journal of Educational Psychology, 89(1), 71-81.

Sloan, L. R., Wilburn, G., Martin, D. E., Fenton, T., Starr, B. J., Craig, K. M., et al. (2003). Intellectual testing in own-group settings can eliminate the effects of perceived test unfairness on stereotype threat influenced reductions in performance. Paper presented at the Hawaii international conference on social sciences, Honolulu, HI. 
Smith, J. L., \& White, P. H. (2001). Development of the domain identification measure: A tool for investigating stereotype threat effects. Educational and Psychological Measurement, 61(6), 1040-1057.

Solorzano, D. G. (1998). Critical race theory, race and gender microaggressions, and the experience of Chicana and Chicano scholars. International Journal of Qualitative Studies in Education, 11(1), 121-136.

Solorzano, D. G., Ceja, M., \& Yosso, T. (2000). Critical race theory, racial microaggressions, and campus racial climate: The experiences of African American college students. The Journal of Negro Education, 69(1), 60-73.

Solorzano, D. G., \& Yosso, T. J. (2001). From racial stereotyping and deficit discourse toward a critical race theory in teacher education. Multicultural Education, 9(1), $2-8$.

Solorzano, D. G., \& Yosso, T. J. (2002). Critical race methodology: Counter-storytelling as an analytical framework for education research. Qualitative Inquiry, 8(1), 2344.

Spencer, S. J., Steele, C. M., \& Quinn, D. M. (1999). Stereotype threat and women's math performance. Journal of Experimental Social Psychology, 35(1), 4-28.

Spielberger, C. D., Edwards, C. D., Montouri, J., \& Lushene, R. (1973). State Trait Anxiety Index for Children (STAIC) test manual. Menlo Park, CA: Mind Garden.

Stangor, C., Carr, C., \& Kiang, L. (1998). Activating stereotypes undermines task performance expectations. Journal of Personality and Social Psychology, 75(5), 1191-1197.

Steele, C. M. (1997). A threat in the air: How stereotypes shape intellectual identity and performance. American Psychologist, 52(6), 613-629.

Steele, C. M. (1999). Thin ice:"Stereotype threat" and Black college students. The Atlantic Monthly, 284(2), 44-54.

Steele, C. M. (2003). Stereotype threat and African-American student achievement. In T. Perry, C. M. Steele \& A. G. Hilliard (Eds.), Young, gifted, and black: Promoting high achievement among African-American students (pp. 109-130). Boston:

Beacon Press.

Steele, C. M., \& Aronson, J. (1995). Stereotype threat and the intellectual test performance of African Americans. Journal of Personality and Social Psychology, 69(5), 797-811. 
Stinson, D. W. (2006). African American male adolescents, schooling (and mathematics): Deficiency, rejection, and achievement. Review of Educational Research, 76(4), 477-506.

Stipek, D., \& Gralinski, J. H. (1996). Children's beliefs about intelligence and school performance. Journal of Educational Psychology, 88(3), 397-407.

Stone, J., Lynch, C. I., Sjomeling, M., \& Darley, J. M. (1999). Stereotype threat effects on Black and White athletic performance. Journal of Personality and Social Psychology, 77(6), 1213-1227.

Strauss, A. L., \& Corbin, J. M. (1998). Basics of qualitative research: Techniques and procedures for developing grounded theory (2nd ed.). Thousand Oaks, CA: Sage Publications.

Tashakkori, A., \& Teddlie, C. (2009). Foundations of mixed methods research: Integrating quantitative and qualitative approaches in the social and behavioral sciences (2nd ed.). Thousand Oaks, CA: Sage.

Tashakkori, A., \& Teddlie, C. (Eds.). (2003). Handbook of Mixed Methods in Social and Behavioral Research. Thousand Oaks, CA: Sage.

Tate, W. F. (1997). Critical race theory and education: History, theory, and implications. Review of Research in Education, 22, 195-247.

Thernstrom, A. M., \& Thernstrom, S. (2003). No excuses: Closing the racial gap in learning. New York: Simon \& Schuster.

Townsend, B. L. (2002). "Testing while Black": Standards-based school reform and African American learners. Remedial and Special Education, 23(4), 222.

U. S. Department of Education (2007). U. S. Department of Education. No Child Left Behind. Retrieved November 7, 2007, from http://www.ed.gov/nclb/landing.jhtml

Villenas, S., \& Deyhle, D. (1999). Critical race theory and ethnographies challenging the stereotypes: Latino families, schooling, resilience and resistance. Curriculum Inquiry, 29(4), 413-445.

Voyager Learning (2008). Voyager Expanded Learning. Voyager Passport K-6 reading intervention system

Retrieved November 6, 2008, from http://www.voyagerlearning.com

Wong, C. A., Eccles, J. S., \& Sameroff, A. (2003). The influence of ethnic discrimination and ethnic identification on African American adolescents' school and socioemotional adjustment. Journal of Personality, 71(6), 1197-1232. 


\section{Appendix A}

On planet Stereo, there are two groups of people, the Greens and the Blues.

In a school on planet Stereo, the Green teachers need to choose a student to compete in a Reading test competition against other schools.

Greens think Blues are not smart.

Will the Green teachers pick a Green student or a Blue student for the Reading test competition?

- The Green teachers will choose a student because

Describe any ways in which Planet Stereo is like the real world: 
Appendix B

Name

Using the following scale, please indicate the number that best describes how much you agree with each of the statements below.

$\begin{array}{ccccc}1 & 2 & 3 & 4 & 5 \\ \text { Strongly } & \text { Disagree } & \text { Undecided } & \text { Agree } & \begin{array}{c}\text { Strongly } \\ \text { Agree }\end{array}\end{array}$

1. I I learn things quickly in Reading classes

2. R__ Reading is one of my best subjects

3. I I get good grades in Reading

4. I I'm hopeless in Reading classes $(R)$

Please indicate the number that best describes you for each of the statements below using the following scale:

$\begin{array}{ccccc}1 & 2 & 3 & 4 & 5 \\ \text { Not at all } & & \text { Somewhat } & & \text { Very Much }\end{array}$

5. How much do you enjoy Reading-related subjects?

6. How important is it to you to be good at Reading?

\section{Circle your answer:}

7. Compared to other students, how good are you at Reading?
a. Very poor
b. Poor
c. About the same
d. Better than average
e. Excellent 
Appendix C

Name

\section{STUDENT SURVEY}

The first question is an example.

I like strawberry ice cream.

1

NOT AT ALL TRUE
2

3

SOMEWHAT TRUE
4 5

VERY TR

HERE ARE SOME QUESTIONS ABOUT YOURSELF AS A STUDENT I CLASS. PLEASE CIRCLE THE NUMBER THAT BEST DESCRIBES $V$ YOU THINK.

58. It's important to me that I don't look stupid in class.

$\begin{array}{ccccc}\mathbf{1} & \mathbf{2} & \mathbf{3} & \mathbf{4} & \mathbf{5} \\ \text { NOt AT ALL TRUE } & & \text { SOMEWHAT TRUE } & & \text { VERY TRUE }\end{array}$

33. One of my goals is to keep others from thinking l'm not smart in class.

$\begin{array}{ccccc}\mathbf{1} & \mathbf{2} & \mathbf{3} & \mathbf{4} & \mathbf{5} \\ \text { NOt AT ALL TRUE } & & \text { SOMEWHAT TRUE } & & \text { VERY TRUE }\end{array}$

51. It's important to me that my teacher doesn't think that I know less than others in clas

$\begin{array}{ccccc}1 & \mathbf{2} & \mathbf{3} & \mathbf{4} & \mathbf{5} \\ \text { NOt AT ALL TRUE } & & \text { SOMEWHAT TRUE } & & \text { VERY TRUE }\end{array}$

55. One of my goals in class is to avoid looking like I have trouble doing the work.

$\begin{array}{ccccc}\mathbf{1} & \mathbf{2} & \mathbf{3} & \mathbf{4} & \mathbf{5} \\ \text { NOT AT ALL TRUE } & & \text { SOMEWHAT TRUE } & & \text { VERY TRUE }\end{array}$


Name

\section{STUDENT SURVEY}

The first question is an example.

I like strawberry ice cream.

1

NOT AT ALL TRUE
2

3

SOMEWHAT TRUE
4 5

VERY TR

HERE ARE SOME QUESTIONS ABOUT YOURSELF AS A STUDENT I CLASS. PLEASE CIRCLE THE NUMBER THAT BEST DESCRIBES $V$ YOU THINK.

1. I'm certain I can master the skills taught in class this year.
NOT AT ALL TRUE
2
$\stackrel{3}{3}$ SOMEWHAT TRUE
4
5
VERY TRUE

11. I'm certain I can figure out how to do the most difficult class work.

$\begin{array}{ccccc}\mathbf{1} & \mathbf{2} & \mathbf{3} & \mathbf{4} & \mathbf{5} \\ \text { NOt At ALL TRUe } & & \text { SOMEWHAt TRUE } & & \text { VERY TRue }\end{array}$

52. I can do almost all the work in class if I don't give up.

$\begin{array}{ccccc}\mathbf{1} & \mathbf{2} & \mathbf{3} & \mathbf{4} & \mathbf{5} \\ \text { NOT AT ALL TRUE } & & \text { SOMEWHAT TRUE } & & \text { VERY TRUE }\end{array}$

56. Even if the work is hard, I can learn it.

$\begin{array}{llccc}\mathbf{1} & \mathbf{2} & \mathbf{3} & \mathbf{4} & \mathbf{5} \\ \text { NOt AT ALL TRUE } & & \text { SOMEWHAT TRUE } & & \text { VERY TRUE }\end{array}$

58. I can do even the hardest work in this class if I try.
NOT AT ALL TRUE
2
3
4
5
SOMEWHAT TRUE
VERY TRUE 


\section{Appendix E}

Focus Group 1

Background:

How old are you?

What is your race?

How long have you been going to this school?

What do you think about this school?

Describe yourself.

How do you think others (teachers, friends, classmates, parents) would describe you as a person?

General Standardized Testing Experiences (Pre):

Describe the FCAT.

What do you think about the FCAT?

What kinds of things do you do on a typical day in school?

Would you make any changes to how you prepare for tests in school?

What might school be like without the FCAT? Why?

What kind of students do well on the FCAT?

How do you think you will do on the FCAT? Why?

Focus Group 2

Stereotype Awareness:

How do you do in school?

How do you do on tests?

How would your friends say you do in school?

What about people who don't know you, how do you think they would say you do in school? Why?

What do these people think about students in this school? Why?

What do people think about students in other schools? Why?

Focus Group 3

Domain-Identification:

What is your best subject?

What subject do you spend the most time on?

How important is it for you to do well on the Reading FCAT? Why?

How do you do compared to most students?

How do you feel about schoolwork related to the Reading FCAT? Why?

What happens in school that makes you feel this way?

Focus Group 4

Anxiety:

How do you feel before right before taking the FCAT?

What do you think makes you feel this way? 
Do you think all students feel this way? Why or why not?

What can be done to make you feel differently?

If you felt differently, how do you think it would affect your FCAT score? Why?

Focus Group 5

Self-efficacy:

Are you confident that you are going to do well in school?

Are you confident that you are going to do well on the FCAT?

What do you think makes you feel this way?

Do you think all students feel this way? Why or why not?

What can be done to make you feel differently?

If you felt differently, how do you think it would affect your FCAT score? Why?

\section{Goal-orientation:}

Do you want to do well in school? Why?

Do you want to do well on the FCAT? Why?

It is important to you for others to think that you are doing well?

Do you try to hide it from others when you don't do well? If so, how?

\section{Focus Group 6}

General Standardized Testing Experiences (Post):

Describe the FCAT.

What did you think about the FCAT?

What kinds of things did you do in school to prepare for the FCAT?

Would you make any changes to how you prepared for the FCAT in school?

What might school be like without the FCAT? Why?

What kind of students do you think did well on the FCAT?

How do you think you did on the FCAT? Why? 
MARTIN J. WASSERBERG

May 19, 1978

2000

2000-2006

2003

2005

2005-2006

2006-2007

2006-2008

2007-2008

2007-2009

2008-2009

2009

2009
Born, White Plains, New York

B.A. with honors, Elementary Education \& Psychology

University of North Carolina at Chapel Hill

Chapel Hill, NC

Elementary Teacher

Miami-Dade Public Schools, Miami, Florida

M.S., Urban Education

Florida International University, Miami, Florida

National Board Teacher Certification

Middle Childhood Generalist

Teacher of the Year, Regional Semifinalist Miami-Dade Public Schools, Miami, Florida

Curriculum Leader and Technology Specialist

Miami-Dade Public Schools, Miami, Florida

Lab Instructor, College of Education

Florida International University, Miami, Florida

Research Assistant, Early Reading First

Florida International University, Miami, Florida

Research Assistant, Project P.O.W.E.R.

FIU Center for Urban Education \& Innovation and

Miami-Dade Public Schools, Miami, Florida

Research Assistant, Algebra Project

Florida International University

Center for Urban Education and Innovation

Miami, FL

Doctoral Evidence Acquisition Fellowship

Florida International University, Miami, FL

Dissertation Year Fellowship

Florida International University, Miami, FL 


\section{PRESENTATIONS AND PUBLICATIONS}

Wasserberg, M. J. (in press). Gender Biases and Nontraditional Literature in the Urban Elementary Classroom. In A. Ginsberg \& S. Brown (Eds.), A New Wave of Male Teachers Reflecting on Gender in K-12 Classrooms: Generating Ideas, Challenging Ideologies, Providing Inspiration.

Rodriguez, L. F. \& Wasserberg, M. J. (under review). From the Classroom to the Country: Engaging Marginalized Youth in Research for Educational Rights. Journal of Urban Education.

Wasserberg, M. J. \& Rodriguez, L. F. (2009). Project POWER: Promoting Our Will through Education and Research. Paper presented at the Eighth Annual Florida International University College of Education Research Conference, Miami, FL.

Wasserberg, M. J. (2009). The Invisible Influence: Stereotypes and the High-Stakes Testing of African American Elementary School Students. Paper presented at the American Educational Research Association Annual Meeting, San Diego, CA.

Wasserberg, M. J. \& Rodriguez, L. F. (2009). Classroom Dialogue Toward Social Justice Outcomes. Paper presented at the American Educational Research Association Annual Meeting, San Diego, CA.

Wasserberg, M. J. (2008). Nontraditional Gender Role Literature as a Catalyst for Dialogically Based Change in an Urban Elementary Classroom. Paper presented at the Florida Association of Teacher Educators Annual Conference, Orlando, FL.

Rodriguez, L. F. \& Wasserberg, M. J. (2008). Project P.O.W.E.R.: Engaging Marginalized Youth in Research Initiatives. Paper presented at the Florida Association of Teacher Educators Annual Conference, Orlando, FL.

Wasserberg, M. J. (2008). No Child Left Behind, Stereotype threat, and the standardized testing of African American third graders. Paper presented at the Seventh Annual Florida International University College of Education Research Conference, Miami, FL.

Wasserberg, M. J. (2008). Gender Biases and Nontraditoinal Literature in the Urban Elementary Classroom. Paper presented at the Seventh Annual Florida International University College of Education Research Conference, Miami, FL.

Wasserberg, M. J. (2008). Stereotype Threat and the Standardized Testing Experiences of African-American Children in an Urban Elementary School. Poster session presented at the American Educational Research Association Annual Meeting, New York, NY. 